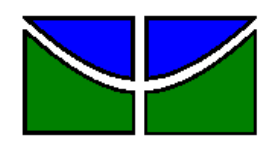

Universidade de Brasília

Faculdade de Economia, Administração e Contabilidade

Departamento de Administração

Curso de Graduação em Administração à Distância

ROBERTO MÁRCIO MAGALHÃES

\title{
MOTIVAÇÃO NO TRABALHO EM TECNOLOGIA DE INFORMAÇÃO: o estudo de caso de uma instituição financeira brasileira
}

Brasília - DF 


\section{ROBERTO MÁRCIO MAGALHÃES}

\section{MOTIVAÇÃO NO TRABALHO EM TECNOLOGIA DE INFORMAÇÃO: o estudo de caso de uma instituição financeira brasileira}

Monografia apresentada ao Departamento de Administração da Universidade de Brasília (UnB) como requisito parcial para obtenção do grau de Bacharel em Administração, na modalidade à distância.

Professora Orientadora: Rose Mary Gonçalves, Mestre

Professora Supervisora do Eixo: Gisela Demo Fiúza, Doutora

Brasília - DF 
Magalhães, Roberto Márcio.

Motivação no trabalho em tecnologia de informação: o estudo de caso de uma instituição financeira brasileira / Roberto Márcio Magalhães. - Brasília, 2011.

38 f. :II.

Monografia (bacharelado) - Universidade de Brasília, Departamento de Administração - EaD, 2011.

Orientador: Prof. Mestre, Rose Mary Gonçalves, Departamento de Administração.

1. Motivação. 2. Expectativa. 3. Força motivacional. I. Título. 


\section{ROBERTO MÁRCIO MAGALHÃES}

\section{MOTIVAÇÃO NO TRABALHO EM TECNOLOGIA DE INFORMAÇÃO: o estudo de caso de uma instituição financeira brasileira}

A Comissão Examinadora, abaixo identificada, aprova o Trabalho de Conclusão do Curso de Administração da Universidade de Brasília do aluno

Roberto Márcio Magalhães

Msc. Rose Mary Gonçalves

Professora Orientadora

Dra. Gisela Demo Fiuza

Professora Examinadora

Brasília, 09 de abril de 2011. 


\section{RESUMO}

As organizações, por melhores resultados, buscam criar um ambiente de trabalho que favoreça a obtenção de maior produtividade no trabalho de seus colaboradores. Por sua vez, a produtividade se relaciona diretamente ao nível de motivação no trabalho experimentado por tais funcionários. Assim, torna-se necessário buscar a identificação dos fatores que estimulem a força motivacional das pessoas. Este trabalho realizou um estudo de caso em uma instituição financeira brasileira para identificação do nível de motivação de seus trabalhadores em um departamento de tecnologia da informação. Através de uma abordagem quantitativa, com uma amostra de 30 trabalhadores, foi aplicado o questionário IMST - Inventário de Motivação e Satisfação no Trabalho - que tem como referência conceitual o Modelo da Expectativa de Vroom, ou Teoria da Expectativa. Foi aplicado também um questionário com perguntas relacionadas ao perfil socioeconômico dos pesquisados. Após a análise dos dados obtidos, o estudo, amparado no valor encontrado para a força motivacional do grupo, identificou que os colaboradores pesquisados possuem um nível regular de motivação. Associando os resultados relativos à força motivacional média dos colaboradores do departamento pesquisado com a força motivacional de subgrupos amostrais organizados a partir das variáveis destacadas pelo diagnóstico socioeconômico, constatou-se certa regularidade entre os resultados, não havendo, portanto, níveis muito diferenciados de motivação em relação a padrões específicos.

Palavras-chave: Motivação. Expectativa. Força Motivacional. 


\section{SUMÁRIO}

1 INTRODUÇÃO

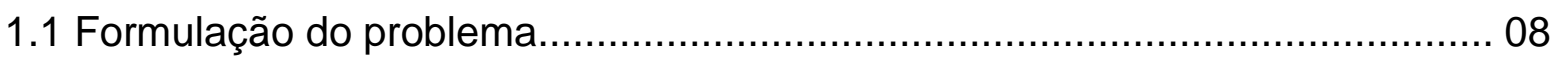

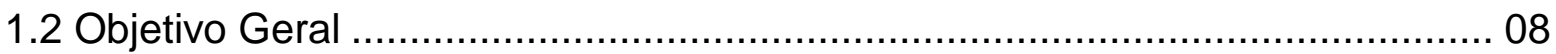

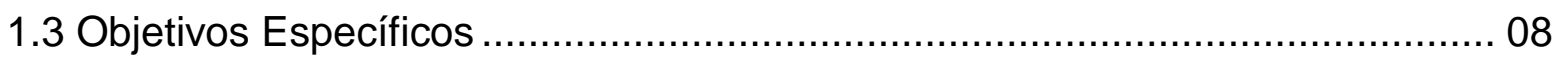

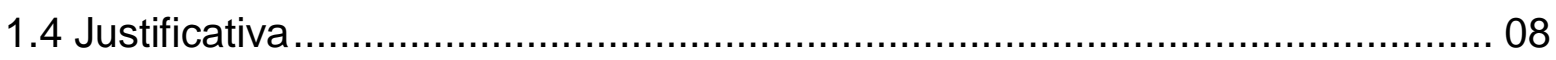

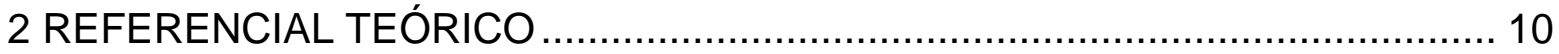

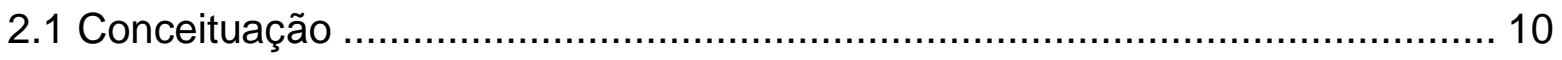

2.2 As teorias da motivação: um enfoque à Teoria das Expectativas de Vroom.... 13

2.3 Pesquisas empíricas sobre motivação no Brasil ............................................. 16

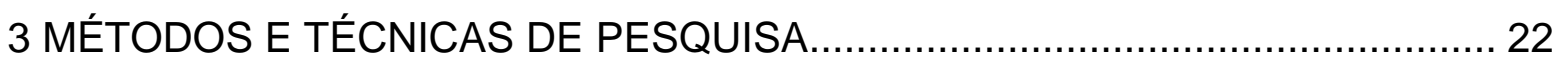

3.1 Caracterização da organização e do objeto de estudo .................................... 22

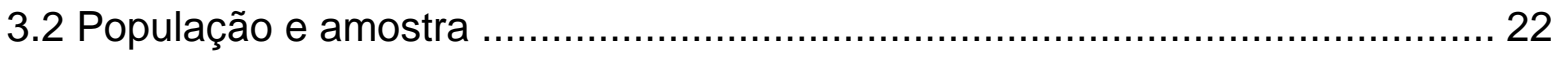

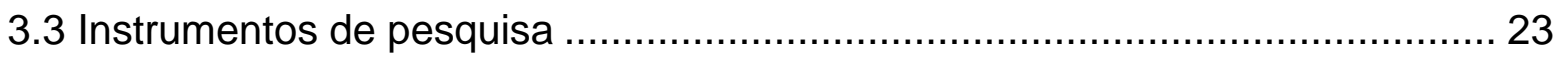

3.4 Procedimentos de coleta e análise de dados ................................................. 24

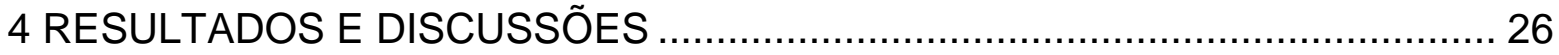

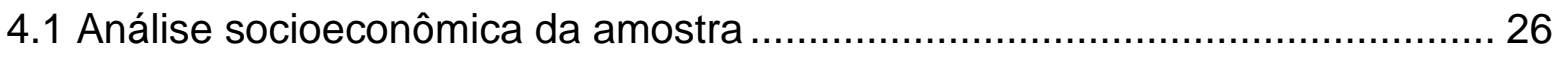

4.2 Análise do nível de motivação dos colaboradores ......................................... 30 
5 CONCLUSÕES E RECOMENDAÇÕES.

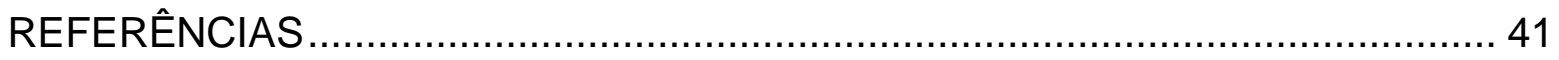

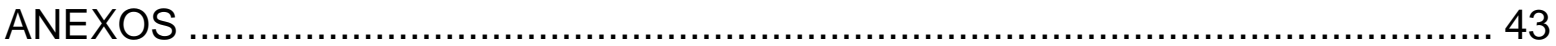

Anexo A - Inventário da Motivação e Significado do Trabalho (IMST) .................. 43 


\section{INTRODUÇÃO}

O avanço tecnológico experimentado pelo mundo nas últimas décadas foi acompanhado do surgimento de uma categoria de profissionais especializados em tecnologia da informação. São profissionais com características bem peculiares e preparados, sobretudo, para lidar com a evolução tecnológica, componente fundamental para a obtenção de melhores resultados nas organizações.

Os profissionais de tecnologia da informação são pessoas que convivem diariamente com as pressões exercidas pelos ambientes organizacionais, sejam elas associadas ao desempenho individual, da equipe ou de toda a empresa. Além disso, necessitam constantemente de atualização e qualificação, considerando que a área exige frequente adaptação, desenvolvimento e domínio de novas tecnologias; não raro em curtos intervalos de tempo.

Outro ponto que deve ser realçado, em relação ao cotidiano do profissional de tecnologia da informação, diz respeito à dinamicidade do negócio em que está envolvido, especialmente se o negócio é relacionado à tecnologia de uma organização do setor bancário. Normalmente o profissional em questão possui pouco tempo para alterar e aperfeiçoar os respectivos sistemas, por conviver com um contexto profissional de frequentes mudanças; sejam referentes a alterações na legislação ou no sistema financeiro, ou ainda em decorrência de decisões governamentais de grande impacto operacional. Essa conjuntura repercute-se no desgaste físico e mental dos envolvidos; gerentes, analistas ou programadores.

Tendo como base os limites e as necessidades desses trabalhadores, as empresas têm investido, cada vez mais, em programas de humanização do ambiente de trabalho. As organizações tentam, em alguma medida, promover condições para que tais profissionais sintam-se motivados ao cumprimento de seus objetivos; mesmo porque, utilizando os argumentos de Maslow (1962), as pessoas motivadas para o crescimento tornam-se muito mais auto-suficientes, senhoras de si, conscientes de sua capacidade e potencialidade. 


\begin{abstract}
As determinantes que governam [os seres humanos] são de natureza interna, em vez de sociais ou ambientais. Elas são as leis de sua própria natureza interna, de suas potencialidades e capacidades, seus talentos, seus recursos latentes, seus impulsos criadores, suas necessidades de conhecerem a si próprias e se tornarem cada vez mais cônscias do que realmente são, do que realmente querem, da natureza de sua vocação ou destino (MASLOW, 1962, p. 53).
\end{abstract}

Quando a pauta em questão é a motivação do corpo funcional de uma organização, seja em um departamento de tecnologia da informação de uma instituição financeira ou em uma empresa familiar, a solução geralmente encontrada passa por duas estratégias: recompensas e estímulos. Esquece-se, porém, que ambas as estratégias são artificiais e que uma análise mais acertada exige uma reflexão sobre as práticas utilizadas pela empresa em relação ao quadro de pessoal.

Em muitas organizações é comum encontrar uma grande quantidade de pessoas que não nutrem a menor motivação por aquilo que fazem, não experimentando no trabalho nenhuma satisfação ou realização pessoal. O emprego, nesses casos, passa a ser visto como uma mera forma de obter recursos que possam fazê-los se sentirem felizes fora dele. Nesse momento a atividade 'trabalho' deixa de ser um referencial de auto-estima e valorização pessoal, tornando-se uma fonte de sofrimento, e não uma oportunidade de realização sadia dos desejos interiores de cada um (BERGAMINI, 2006).

Entre os problemas relacionados ao aspecto motivacional dos trabalhadores de uma empresa, pode-se ressaltar o diferenciado nível de motivação dos colaboradores. É um problema que, entre outras repercussões, exige estratégias específicas dos gestores em relação à motivação dos membros da equipe. Seja devido à idade, à renda mensal, ao tempo de serviço ou ao cargo ocupado; o fato é que no departamento de tecnologia da informação da instituição pesquisada podem coexistir diferentes níveis de motivação, o que, por sua vez, pode ocasionar dificuldades de relacionamentos e outros resultados negativos.

Considerando o ambiente de trabalho em que vivem os profissionais de tecnologia da informação, especialmente os desenvolvedores de aplicativos, e a importância dessas pessoas para a organização, este trabalho estudou o nível de satisfação e motivação dos trabalhadores de um departamento da Unidade de Tecnologia de uma instituição financeira brasileira. Neste estudo foram analisadas as expectativas, 
a valoração atribuída aos fatores motivacionais e a percepção relativa ao próprio desempenho e esforço como influentes para o efetivo resultado do seu trabalho.

\subsection{Formulação do problema}

Neste estudo buscou-se responder à seguinte questão de pesquisa: qual o nível de motivação dos desenvolvedores de aplicativos de um departamento da Unidade de Tecnologia da Informação de uma instituição financeira brasileira?

\subsection{Objetivo Geral}

O objetivo geral desta pesquisa é identificar o nível de motivação no trabalho dos desenvolvedores de aplicativos de um departamento da Unidade de Tecnologia de uma instituição financeira brasileira.

\subsection{Objetivos Específicos}

Os objetivos específicos desta pesquisa são:
a) identificar o perfil dos desenvolvedores de aplicativos do departamento;
b) comparar resultados obtidos com o perfil sociodemográfico dos respondentes.

\subsection{Justificativa}

Entre os desafios enfrentados pelos profissionais de tecnologia da informação, cabe novamente destacar a necessidade constante de atualização e as freqüentes mudanças no contexto de trabalho, motivo de transtornos para trabalhadores e 
organizações. Para não se defasarem em termos de conhecimento tecnológico, os profissionais dividem-se entre o trabalho e a prospecção, restando pouco tempo para dedicarem-se à família, aos amigos e ao lazer. Ademais, as repetidas mudanças no contexto de trabalho a que estão submetidos, muitas vezes acelerando um ritmo de atividades já intenso, é suficiente para alterar os sentidos físicos e psíquicos dessas pessoas.

No plano aplicado, o conhecimento do nível motivacional dos profissionais em referência pode contribuir para que as organizações desenvolvam programas voltados à motivação e satisfação do seu quadro de funcionários. Mais satisfeitos e motivados, e percebendo reflexos positivos na qualidade do seu trabalho, é provável que a produtividade desses colaboradores venha a aumentar, o que beneficiaria os resultados da empresa e atenderia, em última instância, às expectativas de clientes e investidores.

No que tange à importância desse estudo para o contexto acadêmico, cumpre ressaltar que a presente pesquisa pode contribuir para o entendimento da temática aqui abordada nas disciplinas e cursos relacionados. 


\section{REFERENCIAL TEÓRICO}

Inicialmente, e de forma breve, considerando-se o grande número de autores que se dedicaram ao tema, esta seção trata da compreensão de algumas abordagens conceituais sobre a motivação. Em seguida descreve um pouco das principais teorias sobre assunto, dando destaque à Teoria das Expectativas de Vroom, modelo teórico utilizado na pesquisa a ser aplicada. Cabe ressaltar, porém, que as teorias apresentadas, apesar de aparentemente conflitantes, em muitos casos se complementam.

Após a apresentação das teorias da motivação, este trabalho se dedicou a realizar uma revisão das pesquisas empíricas sobre motivação no Brasil. Os autores estudados foram Fernandes e Zanelli (2006), que buscam compreender as identidades dos indivíduos nas organizações e a cultura organizacional; Porto e Tamayo (2003), que discutem os valores relativos ao trabalho; Alves Filho e Borges (2001), que estudam a mensuração da motivação e o significado do trabalho; e Bergamini (1999), que no artigo 'Motivação: mitos, crenças e mal-entendidos' procurou delimitar o que deve ser realmente reconhecido como motivação autêntica, esclarecendo confusões conceituais que podem dificultar o cotidiano de gestão das organizações. Tais obras foram selecionadas para compor esta pesquisa devido a sua inter-relação e adequação com os objetivos propostos.

\subsection{Conceituação}

Os partidários da Administração Científica esboçada por Taylor, por volta de 1911, defendiam o uso de formas de controle sobre os subalternos para que se conseguisse atingir níveis predeterminados de produtividade. Assim sendo, as operações de trabalho tornaram-se cada vez mais simples e rotineiras, começando, em especial, pelo fracionamento dos cargos nas linhas de montagem (BERGAMINI, 2006). 
Àquela época, em lugar do clima de punição, adotou-se a crença de que o dinheiro seria a principal fonte de incentivo à motivação. Acreditou-se que a maioria dos trabalhadores escolheria seus empregos não pelo tipo de trabalho ou pelo conteúdo dos cargos, mas principalmente com base nas perspectivas de remuneração (BERGAMINI, 2006).

A escola de Relações Humanas nos trouxe, por sua vez, que os objetivos motivacionais a serem perseguidos no trabalho orientavam as pessoas a sentiremse úteis e importantes. Para esta escola, era necessário satisfazer o desejo natural dos trabalhadores de se considerarem parte integrante de um grupo social, sem se esquecer do reconhecimento individual a cada um deles na forma pecuniária (BERGAMINI, 2006).

Para Ferreira, Fuerth e Esteves (2006) a conceituação de motivação, assim como o desenho de sua prática, exige argumentos bastante complexos. Para a compreensão do significado do tema, os autores acentuam ser necessário percorrer várias escolas e, partindo-se de seus pressupostos, deve-se buscar uma complementaridade entre seus postulados. É interessante, segundo os autores, interagir as teorias da melhor forma possível para que ambientes organizacionais motivadores sejam criados.

Bergamini (2006) entende que se o desafio das primeiras abordagens dos modelos de administração era desvendar o que se deveria fazer para motivar as pessoas, hoje se percebe que cada indivíduo já traz dentro si, de alguma forma, suas próprias motivações. O objetivo passa a ser a adoção de recursos organizacionais apropriados para não sufocar as forças motivacionais próprias das pessoas, de tal forma que elas não percam a sua sinergia motivacional. Segundo Bergamini (2006), a motivação cobre grande variedade de formas comportamentais, e a diversidade de interesses percebida entre os indivíduos nos permite ver que as pessoas não fazem as mesmas coisas pelas mesmas razões, tendo cada pessoa sua própria orientação motivacional. Ainda que as pessoas experimentem uma relação de amizade próxima e estreita, Bergamini (2006) observa que geralmente elas não compreendem o valor que o outro dá a certos objetivos motivacionais ou a razão de tomar determinadas atitudes. O sentido que cada indivíduo atribui àquilo que faz é próprio apenas daquela pessoa e o significado que ela vê em suas ações guarda estreita ligação com a sua escala pessoal de valores. 
Archer (1997 apud FERREIRA; FUERTH; ESTEVES, 2006), em suas argumentações relacionadas à motivação organizacional, defende que como não é possível uma pessoa motivar a outra, a alternativa é criar um ambiente de trabalho que possa estimular a ação. À administração não caberia motivar os colaboradores, mas induzir comportamentos positivos por parte deles. Tal indução poderia ser realizada por intermédio de ações como:

a) desenvolver programas de relacionamentos visando a valorização do trabalhador;

b) manter os funcionários devidamente informados do que é necessário para que o trabalho seja bem feito;

c) buscar o envolvimento do quadro de funcionários nas decisões que afetam suas funções;

d) estabelecer canais de comunicação eficientes;

e) manter os funcionários cientes da satisfação da gerência com os trabalhos bem realizados e não apenas da insatisfação quando ocorre o inverso;

f) manter políticas de reconhecimento e ascensão profissional baseadas no mérito;

g) remunerar de forma justa e compatível; dentre outras.

Siqueira e Padovam (2008), quando discutem motivação, acentuam a importância do bem estar no trabalho, que segundo eles é composto por três componentes: satisfação, envolvimento e comprometimento organizacional afetivo. Apontam ainda que estes três componentes, já consolidados no campo da Psicologia Organizacional e do Trabalho, representam vínculos positivos com o trabalho e com a organização. Para os autores, funcionários desmotivados não alcançam a satisfação e o envolvimento com o trabalho, não se comprometendo realmente com a organização. Assim, insatisfeitos e descomprometidos, não obtém bem estar no trabalho.

Vergara (2000 apud FERREIRA; FUERTH; ESTEVES, 2006), da mesma forma que Bergamini (2006), também aborda a individualização da motivação, elucidando que, ao mesmo tempo em que existem pessoas altamente motivadas para realizar determinadas tarefas, existem também aquelas que acham as mesmas tarefas 
desinteressantes. Isto decorreria dos diferentes valores, necessidades, interesses, formações profissionais e histórias de vida.

Alves Filho e Caldas (2007) sustentam que todo comportamento humano é motivado e que nas organizações a motivação se refere à vontade de realizar um trabalho ou de se atingir determinado objetivo, ressaltando que os atos motivacionais determinam simultaneamente a direção e a intensidade dos comportamentos. Argumentam ainda que é necessário investir nas pessoas, fazendo com que caminhem na direção dos objetivos organizacionais e tornando-as colaboradoras eficientes e eficazes.

\subsection{As teorias da motivação: um enfoque à Teoria das Expectativas de Vroom}

Vários autores formularam teorias da motivação com base na satisfação de diversas necessidades que influenciam direta ou indiretamente o comportamento humano nas organizações. Entre as teorias pode-se citar a Teoria de Herzberg; a Hierarquia de Necessidades de Maslow; as Teorias X e Y de Douglas McGregor; e a Teoria das Expectativas de Vroom, que é detalhada neste trabalho de forma um tanto mais cuidadosa.

Em relação à Teoria de Herzberg, Cury (2005) afirma que o psicólogo Frederick Herzberg, ao pesquisar as fontes de motivação relacionadas ao trabalho, observou que as pessoas, à medida que adquirem experiência no trabalho e se desenvolvem na profissão, passam a valorizar mais a estima e a autorrealização. A partir destas observações, Herzberg desenvolveu uma teoria de motivação no trabalho baseada em fatores de higiene e de motivação como categorias básicas de necessidades.

A categoria constituída pelos fatores de higiene ou de manutenção descreve o ambiente humano e envolve a função de impedir a insatisfação com o trabalho. Do outro lado, a categoria formada pelos fatores de motivação envolve a mobilização das pessoas para realizações superiores.

A Teoria da Hierarquia das Necessidades de Maslow, também estudada por Cury (2005), entende que o comportamento humano se baseia em suas necessidades. 
Uma vez ativa uma necessidade, ela pode funcionar como estímulo para uma ação, moldando o comportamento e indicando o que será importante ao indivíduo. As necessidades humanas constituem, assim, fonte de motivação.

Maslow dispõe de forma hierárquica cinco sistemas de necessidades. Em ordem ascendente são: necessidades básicas, segurança, associação, ego-status e autorealização (CURY, 2005).

As necessidades básicas relacionam-se a interesses de sobrevivência e a interesses fisiológicos, como roupa, alimentação, abrigo, conforto físico e sexo. Satisfeitas as necessidades básicas, as pessoas passam a se interessar pelas necessidades de segurança, que envolvem benefícios individuais ou familiares, como planos de aposentadoria, assistência médica, política salarial, pensões, condições de higiene e segurança e estabilidade no trabalho (CURY, 2005).

De forma crescente, uma vez satisfeitas as necessidades básicas e de segurança, os indivíduos deixam de lado as preocupações relacionadas a eles próprios e começam a se conscientizar das necessidades de associação; observando a ligação e interdependência existentes entre as pessoas no trabalho, buscando a participação em grupos, a aceitação e a integração à família organizacional. $\mathrm{Na}$ seqüência, sentindo-se agora adaptadas e integradas, as pessoas passam a se preocupar com o status, com o reconhecimento dos demais. Este sistema é denominado por Maslow como ego-status, abrangendo necessidades relacionadas ao amor próprio e à reputação, buscando assim oportunidades para demonstrar o talento e a capacidade, visando recompensas sociais e profissionais (CURY, 2005).

Por fim, uma vez saciado o desejo de reconhecimento, o homem passa a se preocupar com as necessidades presentes no topo da hierarquia, buscando a autoaprovação, considerando então que o potencial e a experiência são necessários para testar a capacidade. Deste modo, parte para trabalhos que envolvem grandes desafios, objetivando experimentar sensações de desenvolvimento pessoal, satisfação e autorrealização (CURY, 2005).

Nas teorias $\mathrm{X}$ e $\mathrm{Y}$, de Douglas McGregor, as divergências entre as metas individuais e as metas das organizações se dão em virtude de tomadas de atitudes gerenciais baseadas em premissas inadequadas em relação aos tipos de motivação envolvidas. A teoria $X$ estabelece que, na concepção dos dirigentes, a maioria das 
pessoas prefere ser liderada e dirigida, a assumir responsabilidades. Os dirigentes reconhecem nos empregados a motivação pelo dinheiro, pela vantagem do emprego e pela ameaça de punição. Em contrapartida, a teoria $Y$ pressupõe que a colaboração humana nas organizações é determinada pela sensibilidade dos dirigentes descobrirem a melhor maneira de utilizar o potencial de trabalho dos funcionários, e não pelos limites próprios da natureza humana (CURY, 2005).

Desenvolvida inicialmente pelo psicólogo Victor Vroom, em 1964, a Teoria das Expectativas defende que o processo de motivação deve ser explicado em função dos objetivos e das opções de cada indivíduo; e das expectativas de atingir esses mesmos objetivos. A teoria das Expectativas contraria as teorias das necessidades, de Maslow e Herzberg, uma vez que estas não levam em consideração as diferenças individuais (ALVES FILHO; BORGES, 2001).

O Modelo da Expectativa de Vroom, conhecido também por Teoria das Expectativas, consagra o conceito de expectativas no campo da motivação e estabelece a existência de uma relação entre o esforço empregado no trabalho com o rendimento obtido, centrando foco no processo de motivar. Para Muchinsky (1994 apud ALVES FILHO; BORGES, 2001), a Teoria da Expectativa proporciona uma base racional e rica para a compreensão da motivação em um determinado trabalho, oferecendo possibilidade ampla de aplicação e prestando-se ao teste empírico.

A Teoria da Expectativa está fundamentada em dois conceitos básicos: valências e instrumentalidade. Por valências entendem-se aqueles valores que os trabalhadores atribuem ao resultado do trabalho, refletindo o quanto desejam ou tem aversão pela obtenção de um determinado resultado, derivando da antecipação da satisfação ou insatisfação com os resultados que são esperados. A instrumentalidade diz respeito ao grau de relação que os trabalhadores percebem entre a execução e a obtenção dos resultados (ALVES FILHO; BORGES, 2001).

Outros dois conceitos da Teoria das Expectativas, segundo Alves Filho e Borges (2001), são a Expectativa e a Força Motivacional. A expectativa diz respeito à percepção do grau do esforço necessário para atingir os resultados esperados, ou grau em que uma pessoa acredite na probabilidade de um determinado resultado. A força motivacional, por sua vez, é a quantidade de esforço necessária para uma pessoa se motivar. 
Do ponto de vista matemático é o produto da valência, o valor instrumental e a expectativa, expressa pela seguinte fórmula: $F M=E[E$ Vi li $]$ onde, $F M=$ Força Motivacional, $\mathrm{E}=$ Expectativa, $\mathrm{V}=$ Valência e $\mathrm{I}=$ Instrumentalidade. $\mathrm{A}$ partir da pontuação (resultado) obtida da força, pode-se considerá-la como o preditor de quão motivado está uma pessoa (ALVES FILHO; ARAÚJO, 2001, p. 61).

Inúmeros estudos têm sido realizados com o objetivo de validar a Teoria das Expectativas, que Madruga (2006) também denomina de Teoria da Expectância. Segundo a autora, a respectiva teoria é atualmente uma das explicações mais amplamente aceitas sobre motivação, sustentando que a "força da tendência para agir de uma determinada maneira depende da força da expectativa de que esta ação trará um resultado, e da atração que esse resultado exerce sobre o indivíduo" (MADRUGA, 2006, p. 16). Ainda segundo Madruga (2006), publicações internacionais recentes têm dado bastante importância à teoria de Vroom como uma maneira de explicar porque muitos trabalhadores não estão motivados no trabalho, produzindo o mínimo necessário.

Enfim, como se pode deduzir, a Teoria da Expectativa revela-se como um bom diagnóstico dos componentes da motivação e possibilita uma base racional de avaliação do esforço investido pela pessoa. Assim sendo, ela parece ser adequada para subsidiar os diagnósticos dos componentes da motivação dos desenvolvedores de aplicativos do departamento da Unidade de Tecnologia pesquisada, proporcionando uma base interessante para avaliar o nível de motivação investido por estas pessoas em seu trabalho.

\subsection{Pesquisas empíricas sobre motivação no Brasil}

Segundo Fernandes e Zanelli (2006), ao compartilhar objetivos, valores e regras, a interação humana nas organizações contribui para construir as identidades dos indivíduos nestas, o que ainda influencia de forma considerável a motivação dos trabalhadores, bem como a sua satisfação e produtividade. Tais identidades são moldadas a partir da apresentação aos funcionários, por parte da empresa, dos seus ritos, crenças, valores, normas, rotinas e tabus, na busca da identificação de colaboradores com os padrões requeridos. Fernandes e Zanelli (2006) também 
procuram alertar que a padronização de atitudes, além das vantagens que representa, uma vez que o ambiente harmônico favorece a produtividade, pode resultar na perda da criatividade e da individualidade, resistência a mudanças e ausência de questionamentos, inibindo o pleno exercício das potencialidades individuais; notadamente em ambientes de mudanças constantes, onde a criatividade e a inovação são fundamentais, como 0 caso do ambiente organizacional estudado nesta pesquisa.

Em relação ao processo de construção das identidades, Fernandes e Zanelli (2006) distinguem a identidade pessoal da identidade social. Eles esclarecem que a primeira se refere à maneira como o indivíduo define suas próprias características, 0 conceito que faz de si, normalmente em comparação com outros indivíduos. A identidade social, por sua vez, diz respeito aos conceitos desenvolvidos pelo próprio indivíduo; resultantes de sua participação em grupos ou categorias; como as identidades derivadas de afiliação étnica, cultural, de gênero, classes sociais, idade, profissionais ou orientação sexual.

Fernandes e Zanelli (2006) compreendem que a convivência em um grupo de trabalho é de grande importância no processo de construção desta identidade social. A experiência no mundo do trabalho, para estes autores, leva os colaboradores de uma organização a incorporar características, valores e hábitos; modificando-os e tornando-os iguais em determinados aspectos, e diferentes, noutros. No estudo, os autores concluem que o que as empresas realmente buscam com práticas de valorização do trabalho em equipe é a ativação de uma identidade de orientação coletiva, fazendo com que os trabalhadores se reconheçam primeiramente como membros da organização na qual trabalham, dando prioridade aos objetivos da empresa, em detrimentos dos objetivos individuais.

Porto e Tamayo (2003) se dedicam a desenvolver e validar uma Escala de Valores relativos ao Trabalho (EVT) e se empenham em realizar um levantamento de instrumentos e entrevistar trabalhadores. Segundo estes autores, citando Schwartz (1999), os valores são definidos como critérios ou metas que transcendem situações específicas, que são ordenados por sua importância e que servem como princípios que guiam a vida do indivíduo. Eles constituem o sistema de valores das pessoas, e pode estar estruturado em dois níveis: o primeiro se refere a uma estrutura geral; e o 
segundo, a estruturas associadas a contextos específicos da vida, como, por exemplo, a família, o trabalho e a religião.

No que se refere aos contextos específicos, Roe e Ester (1999 apud PORTO; TAMAYO, 2003) consideram que o interesse dos pesquisadores nos valores relativos ao trabalho pode ser explicado pela função social do trabalho como principal fonte de renda, bem como base para a participação social, o status social, a saúde, a vida familiar e outros. Entre os autores destacados por Porto e Tamayo (2003) em relação aos valores relativos ao trabalho, deve-se pontuar:

a) Samuel e Lewin-Epstein (1979) - os valores relativos ao trabalho determinam os modos, meios, comportamentos ou resultados que são preferíveis sobre outros;

b) Nord, Brief, Atieh e Doherty (1998) - os valores relativos ao trabalho são componentes importantes da realidade social e influenciam o tipo de trabalho desenhado para as pessoas, a socialização para o trabalho e a forma como as pessoas relacionam o trabalho a outros aspectos da vida;.

c) Kalleberg (1997 apud SAMUEL; LEWIN-EPSTEIN, 1979) - os valores relativos ao trabalho são preferências em relação às recompensas do trabalho;

d) Sagie e Elizur (1996) - os valores relativos ao trabalho são definidos como a importância dada pelos indivíduos a certos resultados obtidos no contexto do trabalho; e

e) Ros, Shwartz e Surkiss (1999) - os valores relativos ao trabalho são os princípios ou crenças sobre comportamentos ou metas desejáveis, hierarquicamente organizados, que guiam as avaliações sobre os resultados e contexto do trabalho, bem como a escolha de alternativas de trabalho.

Porto e Tamayo (2003) adotam uma definição sobre os valores relativos ao trabalho que considera três aspectos relevantes. $O$ aspecto cognitivo diz respeito às crenças sobre o que é ou não desejável no trabalho; o aspecto motivacional expressa interesses e desejos do indivíduo em relação ao seu trabalho; e o aspecto hierárquico consiste na avaliação dos valores numa hierarquia de importância. Os autores conceituam os valores relativos ao trabalho como sendo os princípios ou crenças sobre metas ou recompensas desejáveis, hierarquicamente organizadas, 
que as pessoas buscam por meio do trabalho e que guiam as suas avaliações sobre os resultados, bem como o seu comportamento.

Porto e Tamayo (2003) destacam a contribuição de Schwartz (1992) na definição de uma escala de valores do trabalho: a Escala de Valores de Schwartz. Tal escala se baseia nas necessidades humanas universais, a saber: as necessidades biológicas básicas, de coordenação social, e os requisitos para o bom funcionamento dos grupos. Os resultados apontaram para dez tipos motivacionais. São eles:

a) poder - os indivíduos procuram preservar sua posição social em seu sistema social;

b) auto-realização - o sucesso pessoal é buscado pela demonstração da competência em acordo com as regras sociais;

c) hedonismo - prazer e gratificação;

d) estimulação - busca da novidade e da estimulação em sua vida;

e) autodeterminação - independência do pensamento e da ação;

f) universalismo - compreender e proteger o bem-estar de todos e da natureza;

g) benevolência - bem-estar das pessoas próximas;

h) tradição - respeito e aceitação dos costumes, da cultura ou religião;

i) conformismo - restringir ações que possam magoar outras pessoas ou que possam violar normas e expectativas sociais;

j) segurança - segurança, harmonia, estabilidade social, estabilidade dos relacionamentos.

Em um estudo conjunto do significado do trabalho e da motivação para o trabalho, Alves Filho e Borges (2001), partindo de uma adaptação do Inventário do Significado do Trabalho (IST), desenvolveram o Inventário da Motivação e Significado do Trabalho (IMST) com o objetivo de mensurar de forma simultânea os dois aspectos. A referência conceitual para a elaboração do IMST, que é adotado nesta pesquisa, foi o Modelo da Expectativa de Vroom, conhecido também por Teoria das Expectativas. 
O desenvolvimento do IMST partiu, inicialmente, de um estudo piloto com bancários e profissionais da área de saúde, por meio de entrevistas semiestruturadas que envolveram as seguintes questões básicas (ALVES FILHO;BORGES,2001):

a) O que significa trabalhar para você?

b) Como você gostaria que fosse seu trabalho?

c) O que você não gostaria que ocorresse no seu trabalho?

No campo do significado do trabalho, Alves Filho e Borges (2001) levam em conta duas facetas identificadas por eles nos estudos de Borges (1998) e de Borges e Tamayo (2000), a saber: os atributos descritivos e os atributos valorativos. Os atributos descritivos envolvem a percepção concreta do trabalho na definição de como ele é. Aborda os fatores: êxito e realização pessoal, justiça no trabalho, sobrevivência pessoal e familiar e carga mental. Os atributos valorativos estão associados a uma definição valorativa do trabalho. São eles: exigências sociais, justiça no trabalho, esforço corporal de desumanização, realização pessoal e sobrevivência pessoal e familiar (ALVES FILHO; BORGES, 2001).

O IMST foi aperfeiçoado a partir de seu uso e o formato atual (ALVES FILHO; BORGES, 2003) mensura quatro aspectos: atributos valorativos, expectativas, atributos descritivos e instrumentalidade. Os fatores identificados para estes aspectos, após seu aperfeiçoamento, são:

a) estrutura fatorial dos atributos valorativos - justiça no trabalho, auto-expressão e realização pessoal, sobrevivência pessoal e familiar, desgaste e desumanização;

b) estrutura fatorial das expectativas - auto-expressão e justiça no trabalho, segurança e dignidade, desgaste e desumanização, responsabilidade;

c) estrutura fatorial dos atributos descritivos - auto-expressão, condições de trabalho, responsabilidade, recompensa econômica, desgaste e desumanização;

d) estrutura fatorial da instrumentalidade - envolvimento, justiça no trabalho, desgaste e desumanização, reconhecimento e independência econômica.

O IMST, instrumento utilizado no estudo de Alves Filho e Borges (2001), contém várias perguntas sobre $\mathrm{o}$ trabalho, abordando-o sob várias perspectivas. $\mathrm{O}$ 
instrumento é dividido em três partes: na primeira parte aborda-se o modelo ideal de trabalho, como ele deveria ser; na segunda parte abordam-se as expectativas e a percepção do trabalho como ele é; e na terceira parte, a percepção relativa ao desempenho e sua contribuição para o alcance ou não dos resultados desejados (ALVES FILHO; BORGES, 2001).

Bergamini (1999), em seu trabalho 'Motivação: mitos, crenças e mal-entendidos', procura, entre outros objetivos, esclarecer o domínio concreto e prático da motivação. Para a autora, em algumas situações, especialmente naquelas de especulação intelectual, a motivação autêntica é confundida com condicionamento, o que pode dificultar progressos pretendidos nas organizações.

Algumas tentativas que objetivam compreender o ser humano descolado de sua natureza existencial têm causado, conforme Bergamini (1999), mais confusão do que esclarecimento. Com esse clima de confusão generalizada, com enfoques tão diferentes sobre um mesmo assunto, torna-se quase impossível conciliar pontos de vista tão diferentes e conflitantes.

A multiplicidade de abordagens, no entanto, reflete, sem dúvida alguma, a importância capital desse aspecto tão eminentemente característico do ser humano. Parece, pois, não somente necessário como também oportuno, repensar a motivação, examinando mais uma vez, de maneira suficientemente crítica, o acervo atual básico de conhecimentos sobre o assunto (BERGAMINI, 1999, p. 25). 


\section{MÉTODOS E TÉCNICAS DE PESQUISA}

Quanto à sua natureza, a pesquisa utilizou a abordagem de pesquisa quantitativa que, conforme Zanella (2006), consiste em um método destinado à representatividade numérica, à medição objetiva e à quantificação dos resultados. No que se refere aos fins, esta pesquisa é classificada como descritiva e explicativa, e quanto aos meios, como pesquisa de campo. Observadas as classificações de outros autores, contidas em Zanella (2006), pode ainda ser considerada como pesquisa científica aplicada, na concepção de Ferrari (1982), e como pesquisa diagnóstico, tendo por base a Taxonomia de Schein (1972).

\subsection{Caracterização da organização e do objeto de estudo}

A organização objeto deste estudo é uma instituição financeira estatal brasileira, constituída na forma de sociedade de economia mista, detendo participação acionária majoritária da União. A organização possui um quadro funcional de mais de 100 mil funcionários, distribuídos em mais de 12 mil pontos de atendimentos no Brasil e no mundo. A pesquisa foi realizada em um departamento de desenvolvimento de aplicativos da área de tecnologia da informação dessa instituição.

\subsection{População e amostra}

O departamento é composto por 53 assessores exercendo funções de análise, desenvolvimento, programação e suporte a sistemas de informação e foi escolhido em virtude de sua importância estratégica para a organização, sua diversidade e complexidade de atribuições e pela facilitação concedida pela organização no acesso aos entrevistados. 
A amostragem da pesquisa foi baseada na distribuição normal e consiste em uma amostragem aleatória simples, na qual todos os elementos têm a mesma probabilidade de serem selecionados.

O tamanho da amostra comprende 30 funcionários, com uma margem de erro de $10 \%$ e um nível de confiança de $90 \%$. Em termos de fórmula a amostra foi assim definida:

$$
x=z(c / 100)^{2} r(100-r)
$$

Onde $c$ é o tamanho da população, $r$ é a fração de respostas que se está interessado, e $z(c / 100)$ é o valor crítico para o nível de confiança (cálculo efetuado no sítio eletrônico Raosoft).

\subsection{Instrumentos de pesquisa}

A pesquisa foi realizada a partir da aplicação de um questionário com perguntas fechadas, com vistas a investigar o nível de motivação dos desenvolvedores de aplicativos de um departamento da Unidade de Tecnologia de uma instituição financeira. Foi utilizado o questionário Inventário da Motivação e do Significado do Trabalho (IMST), desenvolvido por Alves Filho e Borges (2001) que objetiva mensurar simultaneamente a motivação e o significado do trabalho.

O questionário IMST, de Alves Filho e Borges (2001), tem como referência conceitual o Modelo da Expectativa de Vroom, também conhecido por Teoria das Expectativas. Ele foi desenvolvido com base no estudo piloto efetuado com bancários e profissionais da área de saúde de Natal $(R N)$ e é composto de 171 itens divididos em três partes, que devem ser respondidos mediante a atribuição de pontos que variam de zero a quatro, numa escala crescente de intensidade ou importância dada pelo entrevistado a cada questão abordada.

A primeira parte do questionário contempla questões relacionadas ao modelo ideal de trabalho, ou seja, como ele deveria ser na visão do entrevistado. Na segunda parte são apresentadas questões inerentes às expectativas do entrevistado quanto ao que ele espera que ocorra no trabalho e o que ele verifica na efetiva realização 
do trabalho. Na terceira e última parte o entrevistado responde questões que procuram medir sua percepção relativa ao próprio desempenho e esforço como relevantes para o alcance dos resultados no seu trabalho.

O IMST é formado por quatro escalas que medem, respectivamente, os atributos valorativos, os atributos descritivos, as expectativas e a instrumentalidade. As duas primeiras escalas se referem a facetas do significado do trabalho; e as duas últimas, a componentes da motivação (ALVES FILHO; BORGES, 2001).

Após um aperfeiçoamento do IMST, Alves Filho e Borges (2003) chegaram ao seguinte formato, adotado nesta pesquisa: A primeira escala (atributos valorativos), com 61 itens, mensura quatro fatores, a saber: (1) Justiça no Trabalho, (2) Autoexpressão e Realização Pessoal, (3) Sobrevivência Pessoal e Familiar e (4) Desgaste e Desumanização. A segunda (atributos descritivos), com 62 itens, aborda cinco fatores: (1) Auto-Expressão, (2) Condições de Trabalho, (3) Responsabilidade, (4) Recompensa Econômica e (5) Desgaste e Desumanização. A terceira escala (expectativas), também de 62 itens, mensura quatro fatores: (1) Auto-Expressão e Justiça no Trabalho, (2) Segurança e Dignidade, (3) Desgaste e Desumanização e (4) Responsabilidade. A quarta e última escala (instrumentalidade), com 48 itens, mensura, também, quatro fatores: (1) Envolvimento, (2) Justiça no Trabalho, (3) Desgaste e Desumanização e (4) Reconhecimento e Independência Econômica.

O IMST foi acompanhado de um questionário com perguntas relacionadas ao perfil socioeconômico dos respondentes. Este questionário abordou questões relacionadas ao sexo, idade, escolaridade, estado civil, renda bruta e tempo de serviço.

\subsection{Procedimentos de coleta e análise de dados}

A aplicação dos questionários foi iniciada no mês de janeiro de 2011 e encerrou-se no mês seguinte. Os questionários (IMST e Sociodemográfico) foram distribuídos no ambiente de trabalho após a autorização da gerência, sendo combinado o prazo de 10 dias para a devolução dos mesmos. Na oportunidade, tendo em vista evitar quaisquer constrangimentos ou influências em relação às respostas, foi esclarecido 
o aspecto acadêmico da pesquisa e a sua não vinculação a qualquer projeto institucional.

Conforme Kerlinger (1980 apud ZANELLA 2006), o processo de análise de dados é definido como a categorização, ordenação, manipulação e sumarização de dados. A descrição e a apresentação dos dados foram feitas no formato de distribuição de freqüência, organizando os dados de acordo com as ocorrências dos resultados observados.

Os dados coletados foram analisados por meio de técnicas de estatística descritiva (como média e desvio padrão, por exemplo), a partir do aplicativo Microsoft Office Excel e apresentados em tabelas e gráficos. Além de contribuir para expor os dados coletados, tais artifícios foram úteis para melhor visualizá-los e facilitar a discussão. 


\section{RESULTADOS E DISCUSSÕES}

Esta seção apresenta uma análise estatística dos resultados da amostra pesquisada. Inicialmente, procura-se entender o viés socioeconômico da amostra, objetivando esclarecer o perfil padrão dos respondentes dos questionários. A seguir, por meio de uma análise do Inventário de Motivação e Significação do Trabalho (IMST), alicerçada nos procedimentos utilizados por Alves Filho e Borges (2003), discute-se o nível de motivação no trabalho dos desenvolvedores de aplicativos do departamento da Unidade de Tecnologia da instituição pesquisada, aliando tais resultados ao perfil socioeconômico dos colaboradores.

\subsection{Análise socioeconômica da amostra}

Dos 30 respondentes, $90 \%$ (27 respondentes) são do sexo masculino, enquanto 10\% (3 respondentes) são do sexo feminino. Houve, portanto, um predomínio de respondentes do sexo masculino, o que pode ser explicado pelo fato de que as mulheres correspondem à minoria dos colaboradores alocados no setor pesquisado (FIG. 1).

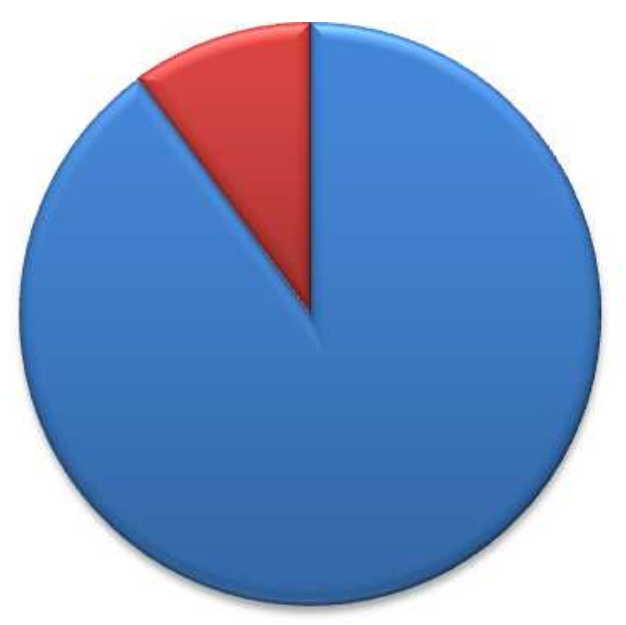

四exo masculino $\square$ sexo feminino

Figura 1 - Sexo dos respondentes Fonte: Do autor, 2011 
Os respondentes são, em maior parte, casados. A amostra revelou o seguinte cenário em relação ao estado civil dos respondentes: $16 \%$ são solteiros, $77 \%$ casados e $7 \%$ separados ou divorciados. (FIG. 2)
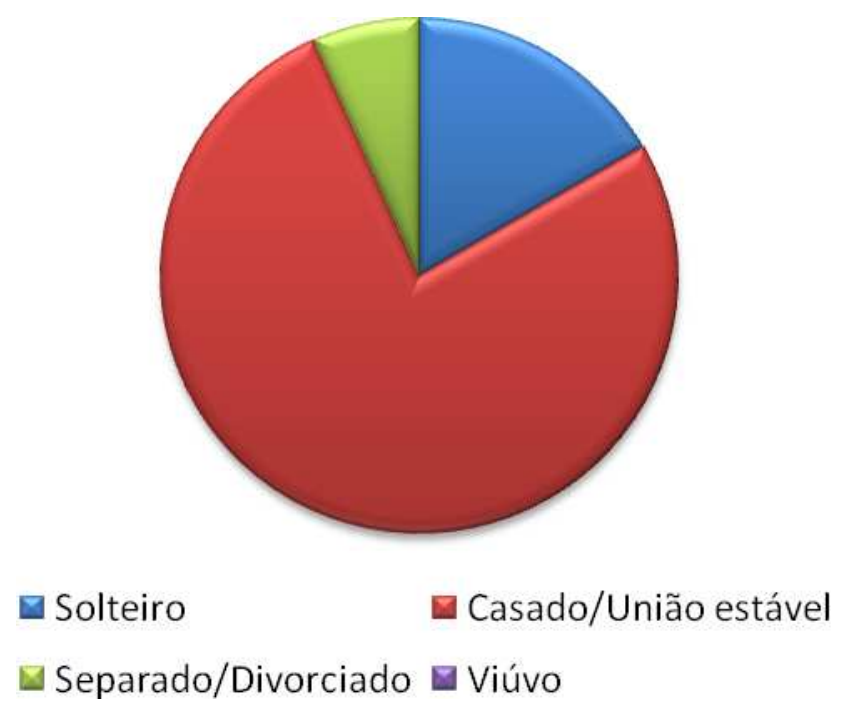

Figura 2 - Estado civil dos respondentes Fonte: Do autor, 2011

A idade dos respondentes situa-se especialmente na faixa entre 18 e 40 anos - 80\% dos respondentes estão concentrados nesta faixa - e apenas 20\% (seis respondentes) localizam-se na faixa entre 41 e 50 anos. Na faixa superior a 50 anos não houve respondentes. (TAB. 1)

Tabela 1 - Idade dos respondentes

\begin{tabular}{lcccc}
\hline \multicolumn{1}{c}{ Idade } & Frequência & $\begin{array}{c}\text { Percentual } \\
(\%)\end{array}$ & $\begin{array}{c}\text { Frequência } \\
\text { acumulada }\end{array}$ & $\begin{array}{c}\text { Percentual } \\
\text { acumulado } \\
(\%)\end{array}$ \\
\hline 18 a 30 completos & 12 & 40 & 12 & 40 \\
31 a 40 completos & 12 & 40 & 24 & 80 \\
41 a 50 completos & 6 & 20 & 30 & 100 \\
A partir de 51 completos & 0 & 0 & 30 & 100 \\
Total & 30 & 100 & - & - \\
\hline
\end{tabular}


Em relação ao tempo de serviço, 15 respondentes encontram-se na faixa de 6 a 10 anos, o que corresponde a $50 \%$ do total. Oito pessoas, o segundo maior número de respondentes por faixa, trabalham no local pesquisado há pelo menos 5 anos, correspondendo a aproximadamente $27 \%$ do total. Cerca de $10 \%$ dos respondentes, três pessoas, indicaram trabalhar na empresa há mais de 10 anos, sendo que uma delas, há mais de 16 anos. (TAB. 2)

Tabela 2 - Tempo de serviço dos respondentes

\begin{tabular}{lcccc}
\hline \multicolumn{1}{c}{ Tempo de serviço } & Frequência & $\begin{array}{c}\text { Percentual } \\
(\%)\end{array}$ & $\begin{array}{c}\text { Frequência } \\
\text { acumulada }\end{array}$ & $\begin{array}{c}\text { Percentual } \\
\text { acumulado } \\
(\%)\end{array}$ \\
\hline Até 5 anos & 8 & 26,7 & 8 & 26,7 \\
De 6 a 10 anos completos & 15 & 50,0 & 23 & 76,7 \\
$\begin{array}{l}\text { De } 11 \text { a } 15 \text { anos completos } \\
\text { De 16 a } 20 \text { anos completos }\end{array}$ & 2 & 6,8 & 25 & 83,5 \\
$\begin{array}{l}\text { A partir de } 21 \text { anos } \\
\text { completos }\end{array}$ & 4 & 3,3 & 26 & 86,8 \\
Total & 30 & 13,2 & 30 & 100,0 \\
\hline
\end{tabular}


Quanto ao grau de escolaridade, o conjunto de respondentes é constituído por pessoas com nível de escolaridade de graduação (mais de 53\%), pós-graduação (mais de 33\%) e nível médio (mais de 13\%). Somando-se os percentuais de respondentes com graduação e pós-graduação, tem-se mais de $86 \%$ do total de respondentes, o que indica tratar-se de uma amostra de indivíduos com alto grau de escolaridade. (FIG. 3)

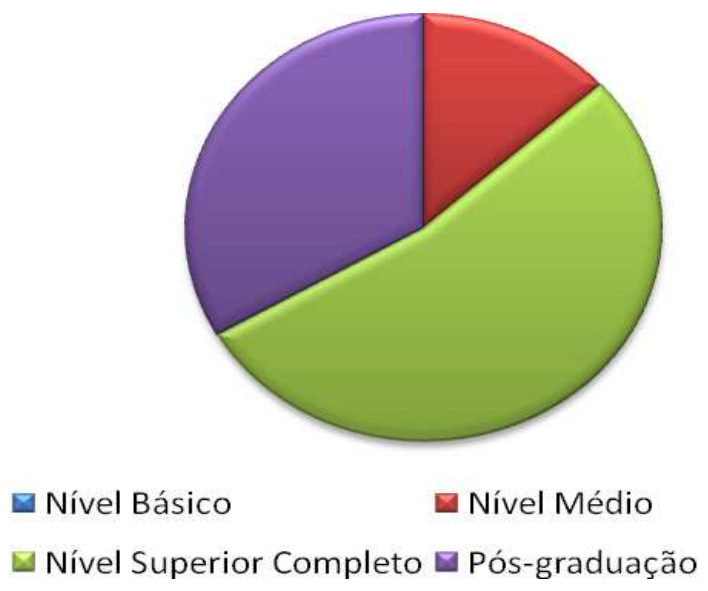

Figura 3 - Escolaridade dos respondentes Fonte: Do autor, 2011

A renda bruta da amostra varia entre os intervalos 'até 10 salários mínimos' até a faixa 'de 15 a 20 salários mínimos'. Um respondente assumiu possuir renda bruta mensal 'até 10 salários mínimos'; 18 respondentes declararam renda bruta mensal 'de 10 a 15 salários mínimos' e 11 pessoas 'de 15 a 20 salários mínimos'. Nenhum respondente assumiu possuir renda bruta mensal 'acima de 20 salários mínimos'. (TAB. 3)

Tabela 3 - Renda mensal bruta dos respondentes

\begin{tabular}{lcccc}
\hline \multicolumn{1}{c}{ Salários mínimos } & Frequência & $\begin{array}{c}\text { Percentual } \\
(\%)\end{array}$ & $\begin{array}{c}\text { Frequência } \\
\text { acumulada }\end{array}$ & $\begin{array}{c}\text { Percentual } \\
\text { acumulado } \\
(\%)\end{array}$ \\
\hline Até 10 & 1 & 3,3 & 1 & 3,3 \\
De 10 a 15 & 18 & 60 & 19 & 63,3 \\
De 15 a 20 & 11 & 36,7 & 30 & 100,0 \\
Acima de 20 & 0 & 0 & 30 & 100,0 \\
Total & $\mathbf{3 0}$ & $\mathbf{1 0 0}$ & - & - \\
\hline
\end{tabular}


O perfil mais comum na amostra é, portanto, um colaborador do sexo masculino (90\%), casado (77\%), com idade entre 18 e 40 anos (80\%) e com um tempo de serviço na instituição entre seis e 10 anos (50\%). É um profissional com nível superior $(86 \%)$ e que possui uma renda bruta mensal de 10 a 15 salários mínimos $(60 \%)$.

\subsection{Análise do nível de motivação dos colaboradores}

Para a análise do nível de motivação no trabalho dos desenvolvedores de aplicativos do departamento da Unidade de Tecnologia da instituição pesquisada, foram reproduzidos os procedimentos utilizados por Alves Filho e Borges (2001 e 2003), acrescidos da análise das associações feitas com o perfil socioeconômico dos colaboradores.

O Inventário de Motivação e Significação do Trabalho (IMST), instrumento utilizado nesta pesquisa, apresenta uma série de questões para as quais os colaboradores atribuíram respostas em uma escala que foi de zero a quatro. A escala dos atributos valorativos, uma definição sobre o que o trabalho deve ser, é representada por 61 questões descritas na primeira parte do questionário. A escala dos atributos descritivos, uma designação da percepção do trabalho de como ele é concretamente, é representada por 62 questões descritas na segunda parte do questionário (Ocorre). No que diz respeito aos componentes da motivação, a estrutura fatorial das Expectativas, descrita também na segunda parte do questionário (Espero), está representada por 62 questões. A Instrumentalidade, contida na terceira parte do questionário, é composta por 48 questões.

Grupos de questões, sejam relacionados aos atributos valorativos ou descritivos, sejam relacionados aos componentes da motivação, Expectativa e Instrumentalidade, formam fatores. A força motivacional encontrada deu-se por meio do produto dos somatórios dos escores nos fatores de Expectativas e o somatório dos escores nos fatores de Instrumentalidade, conforme a fórmula: $\mathrm{FM}=$ $E\left[\Sigma V_{i} l_{i}\right]$, onde "FM" representa a Força Motivacional, "E" a Expectativa, "l" a Instrumentalidade e 'V' a valência. 
A análise dos componentes do IMST foi realizada pela média dos pontos que cada participante atribuiu aos itens de cada fator. Em seguida, calcularam-se os desviospadrão da amostra para os mesmos. As valências dos resultados do trabalho foram tomadas dos escores dos atributos valorativos, constantes no IMST. (TAB. 4)

Tabela 4 - Fatores valorativos

\begin{tabular}{lcc}
\hline \multicolumn{1}{c}{ Fator } & Média & $\begin{array}{c}\text { Desvio } \\
\text { Padrão }\end{array}$ \\
\hline Justiça no trabalho & 3,1 & 0,4 \\
Auto-expressão e realização pessoal & 3,3 & 0,4 \\
Sobrevivência pessoal e familiar & 3,0 & 0,6 \\
Desgaste e desumanização & 2,3 & 1,0 \\
\hline
\end{tabular}

Fonte: Do autor, 2011

Os três fatores mais valorizados revelaram médias bem próximas, o que implica em valorização equivalente atribuída pelos colaboradores. A média mais alta dos fatores valorativos, uma definição sobre o que o trabalho deve ser, foi 3,3 - Autoexpressão e realização pessoal - que define que o trabalho deveria proporcionar oportunidade de expressão, além de reconhecimento, respeito e crescimento pessoal. O fator seguinte, 'Justiça no trabalho', que define o ambiente de trabalho como garantidor de condições materiais, de higiene, de equipamentos e de retorno econômico compatível, obteve a média 3,1 (ALVES FILHO; BORGES, 2003).

O fator 'Sobrevivência pessoal e familiar', que define que o trabalho deve garantir condições econômicas de sobrevivência e de sustento, apresentou média de 3,0. Finalmente, o fator 'Desgaste e desumanização' apresentou média de 2,3; revelando que os colaboradores do departamento pesquisado entendem que o trabalho não deve necessariamente representar um fardo, implicando em desgaste, pressa e desumanização (ALVES FILHO; BORGES, 2003). 
A estrutura fatorial das Expectativas, que define o quanto se espera que o trabalho apresente o devido resultado, é representada por quatro fatores, a saber: 'Autoexpressão e Justiça no trabalho', 'Segurança e dignidade', 'Desgaste e desumanização' e 'Responsabilidade'. A maior média encontrada foi no fator 'Autoexpressão e Justiça no trabalho', enquanto a menor média foi identificada no item 'Desgaste e desumanização' (TAB. 5) (ALVES FILHO; BORGES, 2003).

Tabela 5 - Fatores de Expectativa

\begin{tabular}{lcc}
\hline \multicolumn{1}{c}{ Fator } & Média & $\begin{array}{l}\text { Desvio } \\
\text { Padrão }\end{array}$ \\
\hline Auto-expressão e Justiça no trabalho & 3,61 & 0,15 \\
Segurança e Dignidade & 3,48 & 0,7 \\
Desgaste e desumanização & 1,91 & 0,99 \\
Responsabilidade & 3,4 & 0,4 \\
\hline
\end{tabular}

Fonte: Do autor, 2011

O item 'Auto-expressão e Justiça no trabalho', apresentou o menor desvio padrão, $(0,15)$, ou seja, há pouca heterogeneidade na amostra em relação às questões deste item. O fator foi seguido pelo item 'Responsabilidade', que expressa a percepção dos colaboradores em relação ao cumprimento da tarefa, as responsabilidades das decisões e dignidade $(0,4)$ e pelo fator 'Segurança e dignidade', com 0,7 de desvio padrão (TAB. 6) (ALVES FILHO; BORGES, 2003).

Novamente, a exemplo do que foi constatado na estrutura fatorial dos fatores valorativos, constata-se que o colaborador do departamento pesquisado não espera que seu trabalho o faça ficar extremamente ocupado, apressado, esgotado ou desumanizado.

As médias obtidas para os demais fatores mostraram-se bem próximas, revelando que os colaboradores os esperam de forma aproximadamente igual, numa escala de importância. 
A Instrumentalidade, que diz respeito a quanto o que se obtém do trabalho depende do desempenho ou esforço do colaborador, demonstrou seu índice mais alto no fator Envolvimento, $(3,0)$, que indica quanto os funcionários percebem-se produtivos, incluídos na equipe. O item 'Reconhecimento e independência econômica' vem logo em seguida, com 2,9, e representa o reconhecimento do que se faz e a garantia do sustento (ALVES FILHO; BORGES, 2003).

Tabela 6 - Fatores de Instrumentalidade

\begin{tabular}{lcc}
\hline \multicolumn{1}{c}{ Fator } & Média & $\begin{array}{c}\text { Desvio } \\
\text { Padrão }\end{array}$ \\
\hline Envolvimento & 3,0 & 0,3 \\
Justiça no trabalho & 2,5 & 0,3 \\
Desgaste e desumanização & 1,7 & 0,6 \\
Reconhecimento e Independência Econômica & 2,9 & 0,4 \\
\hline
\end{tabular}

Fonte: Do autor, 2011

O terceiro fator com maior média é a 'Justiça no trabalho', $(2,5)$, que indica quanto os indivíduos percebem o próprio desempenho como influente para garantir conforto, recompensas, salário, entre outros. Em último, aparece o fator 'Desgaste e desumanização' que representa a percepção do próprio desempenho ser responsável pelo seu desgaste e desumanização (ALVES FILHO; BORGES, 2003).

Aqui se reforça o sentimento predominante no grupo em relação ao fator Desgaste e Desumanização, já detectado nas Estruturas Fatoriais dos Atributos Valorativos e das Expectativas. Os colaboradores não valorizam nem esperam o desgaste e a desumanização; bem como não enxergam o próprio desempenho como preponderante para que se atinja tal condição. Tais constatações sugerem a necessidade de serem cuidadosamente observadas e dosadas, por parte da organização, dentre outras características, as condições, o ritmo exigido e a carga adequada de trabalho, em relação à categoria de profissionais estudada. 
Ao comparar os fatores valorativos, as Expectativas e a Instrumentalidade, verificouse que os valores de Expectativas são os que apresentam maior média, enquanto a Instrumentalidade apresenta os menores valores. Isso indica que os colaboradores não percebem com grande intensidade o próprio esforço como determinante para os resultados. (FIG. 4)

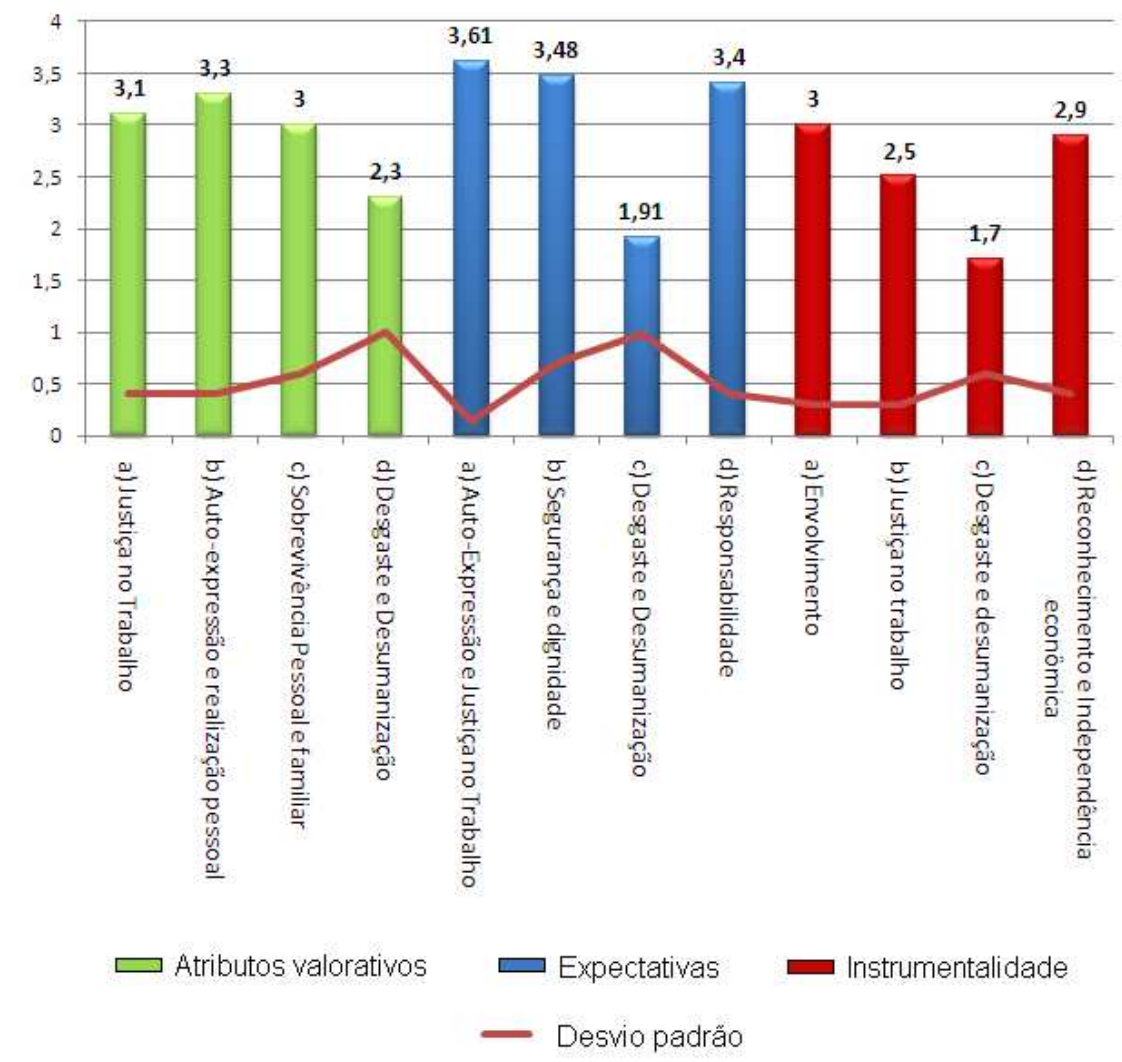

Figura 4 - Médias e desvios padrão dos atributos valorativos, da Expectativa e da Instrumentalidade por fator

Fonte: Do autor, 2011

Aplicando a fórmula para estimar a Força Motivacional (FM) encontrou-se o resultado de 125,24, valor inferior, por exemplo, à média da FM encontrada por Alves Filho e Borges (2007) em estudo que investigou a força motivacional de funcionários técnico administrativos de uma Instituição de ensino superior $(160,16)$. Concluiu-se, porém, tomando por base os parâmetros do estudo citado (em que a FM mínima encontrada foi 82,80; a máxima 212,36 e a média 160,16) que o nível motivacional dos pesquisados, medido pela Força Motivacional (FM), pode ser considerado regular. Há de se ressaltar, no entanto, que os valores encontrados sugerem, à organização pesquisada, a adoção de medidas apropriadas no intuito de buscar o aumento da força motivacional de seus colaboradores. Outro ponto a se destacar é que o fator Expectativa foi o maior responsável pela elevação da média. 
Tendo em vista averiguar o nível de motivação entre os diferentes tipos de pessoas pesquisados, procurou-se ainda entender a força motivacional dos colaboradores pesquisados conforme o perfil socioeconômico. Procurou-se compreender até que ponto o nível de motivação dos colaborados está relacionado a uma condição social ou econômica específica.

Comparando os respondentes do sexo masculino com os do sexo feminino, mesmo reconhecendo o tamanho reduzido dos respondentes deste último sexo, comprovouse estatisticamente que os homens possuem força motivacional ligeiramente maior que as mulheres. Os respondentes do sexo masculino apresentaram $F M=126,38$ e os respondentes do sexo feminino apresentaram $\mathrm{FM}=124,36$.

Em relação à faixa etária dos colaboradores, aqueles com idade entre 18 e 30 anos foram os que apresentaram a Força Motivacional mais elevada, $(130,267)$. Os mais jovens foram seguidos pelos respondentes com idade entre 31 e 40 anos e, logo em seguida pelos respondentes entre 41 e 50 anos. (FIG. 5)

Tais números indicam que a força motivacional é nitidamente maior nos colaboradores de menor idade, indicando que a organização deve buscar implementar medidas compensatórias voltadas para o aumento da motivação naqueles funcionários de maior faixa etária.

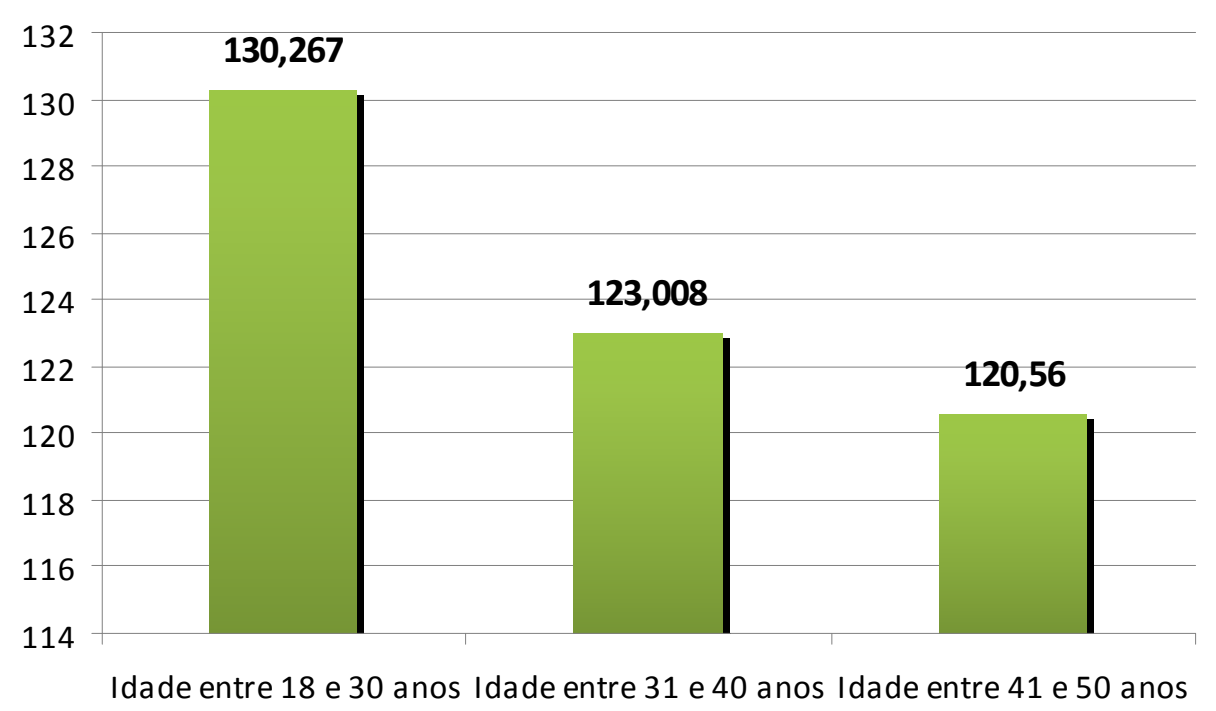

Figura 5 - Força Motivacional por idade Fonte: Do autor, 2011 
Aplicando a fórmula para estimar a Força Motivacional (FM) dos componentes da amostra a partir dos intervalos de escolaridade definidos no questionário socioeconômico aplicado aos colaboradores, tem-se o seguinte quadro: os respondentes que declararam possuir apenas o nível médio apresentam uma FM de 106,115 ; os que possuem ensino superior completo, 122,654; e os que declararam possuir pós-graduação apresentaram uma FM de 137,138.

A diferença significativa detectada no aumento da Força Motivacional, conforme aumenta o nível de escolaridade, configura-se num dado relevante desta pesquisa, podendo sugerir à organização pesquisada o estímulo à formação acadêmica dos seus colaboradores em tecnologia da informação.

Outra associação realizada entre a Força Motivacional (FM) dos desenvolvedores de aplicativos do departamento analisado e o perfil socioeconômico dos mesmos, refere-se ao estado civil. Os cálculos demonstraram não haver maiores diferenças em relação à quantidade de esforço ou pressão de uma pessoa para motivar-se, se casada/união estável ou se solteira. A análise, que ignorou os dados de respondentes separados/divorciados e viúvos, devido a pouca freqüência estatística destes respondentes, apresentou FM semelhante para casados e solteiros. (TAB. 7)

Tabela 7 - Força motivacional segundo estado civil

\begin{tabular}{lc}
\hline \multicolumn{1}{c}{ Estado Civil } & Força motivacional \\
\hline Casado/União Estável & 124,029 \\
Solteiro & 124,923 \\
\hline
\end{tabular}

Fonte: Do autor, 2011

Quando a amostra foi dividida em subgrupos amostrais que compararam a renda bruta dos respondentes e a Força Motivacional (FM) identificada, os indivíduos que declararam possuir uma renda bruta entre '10 até 15 salários mínimos' apresentaram uma FM de 127,539. Os colaboradores que declararam receber entre '15 e 20 salários míninos’ possuem FM um pouco inferior, 124,904. Foi possível estabelecer tal análise apenas para os respectivos intervalos de renda, considerando que os demais intervalos ('Até 10 salários mínimos' e 'Superior a 20 salários mínimos') não apresentaram respondentes suficientes para tal síntese. 
Em relação à Força Motivacional associada ao tempo de serviço declarado pelos respondentes, identificou-se uma relação não linear entre as duas variáveis. Nesta análise, em razão de alguns intervalos descritos no questionário não apresentarem qualquer freqüência, agrupou-se as faixas 'De 11 a 15 anos completos', 'De 16 a 20 anos completos' e 'A partir de 21 anos completos' em um único grupo, a saber: 'A partir de 10 anos'. (TAB. 8)

Tabela 8 - Força motivacional segundo tempo de serviço

\begin{tabular}{lc}
\hline \multicolumn{1}{c}{ Tempo de Serviço } & Força motivacional \\
\hline Até cinco anos & 130,774 \\
De seis a 10 anos & 122,699 \\
Acima de 10 anos & 125,248 \\
\hline
\end{tabular}

Fonte: Do autor, 2011 
Numa associação concomitante entre os resultados da Força Motivacional média dos colaboradores do departamento pesquisado e da Força Motivacional de subgrupos amostrais organizados a partir das variáveis destacadas pelo diagnóstico socioeconômico - sexo, idade, escolaridade, estado civil, renda bruta e tempo de serviço - identificou-se certa regularidade entre os resultados. As exceções foram os respondentes com nível médio de escolaridade, que apresentaram $F M=106,115$; bem abaixo da média total $(125,24)$, e aqueles respondentes com pós graduação, que apresentaram FM =137,138. (FIG. 6)

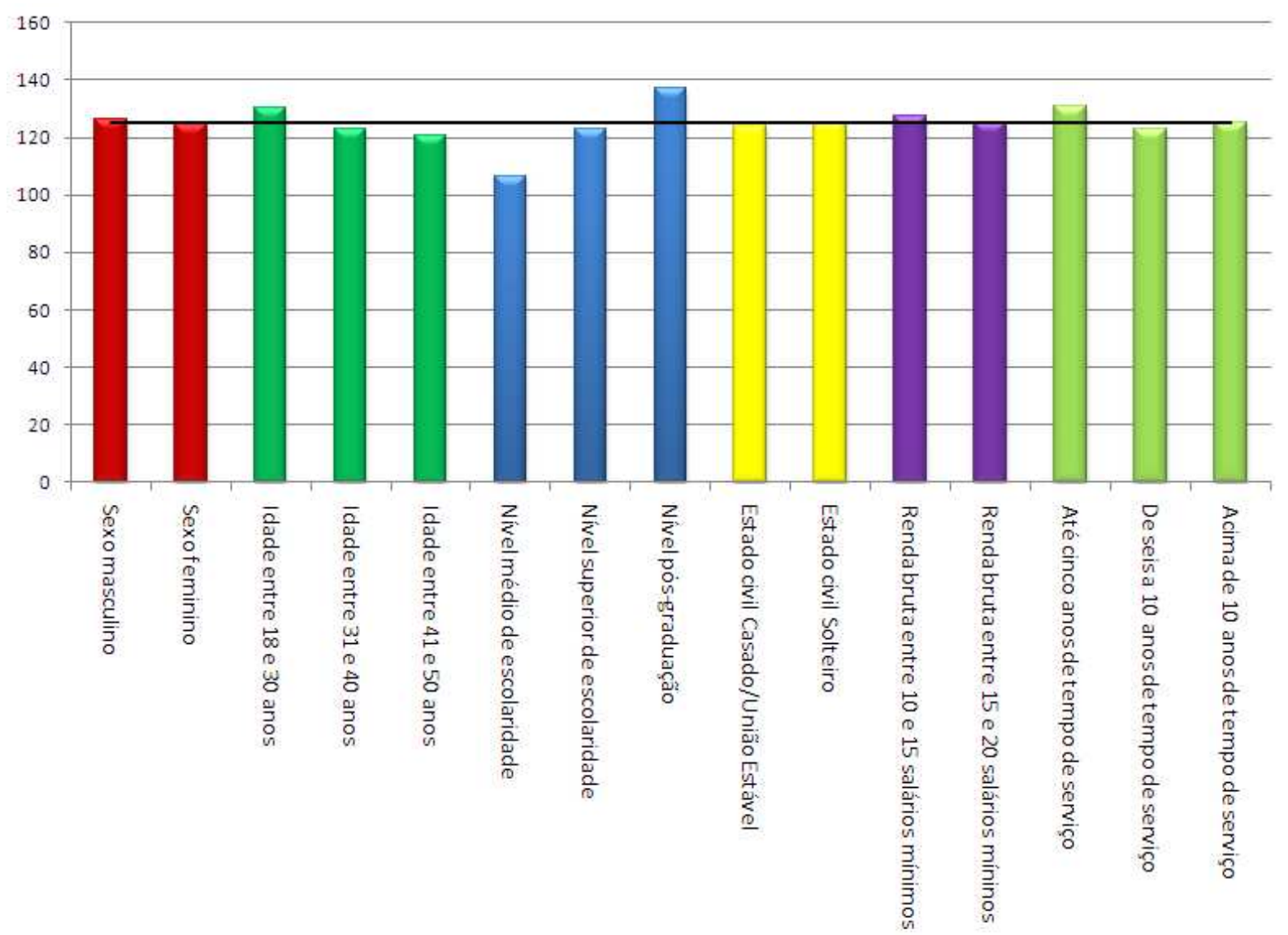

-Força motivacional total dos respondentes $(125,24)$

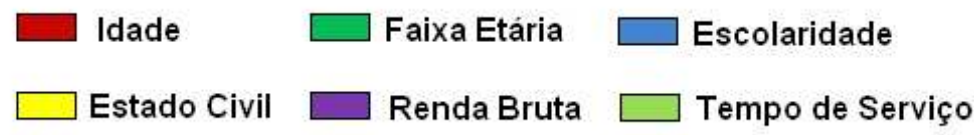

Figura 6 - Força Motivacional (FM) da amostra por sub-grupo amostral Fonte: Do autor, 2011 


\section{CONCLUSÕES E RECOMENDAÇÕES}

O objetivo geral desta pesquisa foi identificar o nível de motivação no trabalho dos desenvolvedores de aplicativos de um departamento da Unidade de Tecnologia de uma instituição financeira brasileira. Assim sendo, pautando-se na revisão bibliográfica explorada para esta pesquisa e associando-a aos resultados encontrados por meio da análise dos questionários aplicados, pode-se dizer que 0 nível de motivação dos trabalhadores do departamento pesquisado é regular. Com a pesquisa se esclareceu que os colaboradores pesquisados atribuem seu aspecto motivacional, principalmente, à oportunidade de se expressar, de garantir o sustento da família e de sentir prazer com o seu trabalho.

Quanto aos objetivos específicos demarcados para esta pesquisa, conseguiu-se conhecer o perfil dos desenvolvedores de aplicativos do departamento pesquisado, ou pelo menos dos respondentes. Como identificado em seção anterior, o perfil mais comum consistiu em um colaborador do sexo masculino, casado, com idade entre 18 e 40 anos, com um tempo de serviço na instituição entre seis e 10 anos, de nível de instrução superior, com renda bruta mensal de 10 a 15 salários mínimos. A associação entre os resultados obtidos com o IMST e aqueles obtidos com o questionário sociodemográfico, revelou particularidades que poderão contribuir com a organização pesquisada em suas estratégias corporativas no campo da motivação, conforme recomendações destacadas adiante.

O IMST, de grande importância para esta pesquisa, subsidiou todas as análises dos componentes da motivação diagnosticadas nos desenvolvedores de aplicativos do departamento analisado. O respectivo instrumento, no contexto desta pesquisa, constituiu-se na ferramenta utilizada para medir o nível de motivação investido pelos trabalhadores, elemento indispensável à consecução dos objetivos traçados por este estudo, não obstante certa complexidade em seu cálculo final.

Os resultados desta pesquisa se caracterizaram como uma análise preliminar e embora tenha demonstrado resultados satisfatórios em relação ao nível de motivação no trabalho dos trabalhadores pesquisados, seria pertinente a ampliação do mesmo para que os dados da análise pudessem ser confirmados por meio de 
outros estudos. Uma análise mais assertiva acerca do nível de motivação dos colaboradores exigiria uma reflexão sobre as práticas utilizadas pela instituição pesquisada em relação à gestão de pessoal. Não tendo sido possível uma empreitada nesse sentido, esse tema fica recomendado como agenda para pesquisas futuras.

Para a organização pesquisada recomendar-se-ia a busca contínua de um ambiente de trabalho motivador, que induza comportamentos positivos por parte de seus colaboradores. Tal condição poderia ser alcançada, por exemplo, através da adoção de ações que objetivem a valorização do trabalhador, buscando seu envolvimento, com políticas de reconhecimento e de ascensão profissional baseadas no mérito. Afinal, conforme ressaltou Archer (1997 apud FERREIRA; FUERTH; ESTEVES, 2006), não é possível uma pessoa motivar a outra, a alternativa é criar um ambiente de trabalho que possa estimular a ação. Como identificado no capítulo anterior, o nível de motivação dos colaboradores pode ser melhorado. Ênfase especial poderá ainda ser dedicada a algumas situações destacadas, como a motivação relacionada à faixa etária e ao nível de instrução dos colaboradores.

Embora este trabalho tenha se amparado na Teoria das Expectativas, há que se considerar e ressaltar a importância do conhecimento das demais abordagens e teorias sobre motivação para o aprofundamento no estudo do tema por parte das organizações. Algumas dessas teorias foram aqui referenciadas, como a Teoria de Herzberg; a Hierarquia de Necessidades de Maslow; e as Teorias X e Y de Douglas McGregor. Conforme destacam Ferreira, Fuerth e Esteves (2006), para que ambientes organizacionais motivadores sejam criados é interessante interagir as teorias da melhor forma possível, buscando uma complementaridade entres seus postulados.

Enfim, as organizações buscam pessoas que estejam satisfeitas, motivadas. É a motivação que impulsiona o indivíduo a apresentar respostas satisfatórias às suas ações. Neste sentido, entende-se que esta pesquisa obteve elementos importantes para a elaboração de um diagnóstico motivacional do departamento em referência, podendo, como já ressaltado, subsidiar políticas e ações de gestão de pessoal e contribuir para a construção teórica do assunto (ALVES FILHO; CALDAS, 2007). 


\section{REFERÊNCIAS}

ALVES FILHO, Antônio; BORGES, Lívia de Oliveira. A mensuração da motivação e do significado do trabalho. Universidade Federal do Rio Grande do Norte. Estudos de Psicologia, 2001, 6(2), 177-194.

A estrutura fatorial do Inventário do Significado e Motivação do Trabalho IMST. Avaliação Psicológica, 2003, 123-145.

ALVES FILHO, Antônio, CALDAS; Rosana Karla Pereira. Fatores motivacionais determinantes do vínculo com o trabalho: o caso de uma instituição de ensino superior. Revista da FARN, Natal, v. 6, n. 1/2, p. 53-67, jan./dez. 2007.

BERGAMINI, Cecília W. Motivação nas Organizações. 4a․ ed. São Paulo: Atlas, 2006.

- Motivação: mitos, crenças e mal-entendidos. Revista de Administração de Empresas. São Paulo, 30(2), abr./jun, 1999, p. 23-34.

CURY, Antônio. Organização \& Métodos - Uma Visão Holística. 8ª . ed. São Paulo: Atlas, 2005.

FERNANDES, Karina Ribeiro; ZANELLI, José Carlos. O Processo de Construção e Reconstrução das Identidades dos Indivíduos nas Organizações. RAC, Curitiba, v.10, n.1, Jan/Mar. 2006: 55-72.

FERREIRA, André; FUERTH, Leonardo Ribeiro; ESTEVES, Rodrigo Clebicar Pereia Mota. Fatores de Motivação no Trabalho: O Que Pensam os Líderes. EnANPAD 2006, Set. 2006.

MADRUGA, Elda Lúcia Paiva. A motivação dos funcionários do Banco do Brasil na Região Metropolitana do Recife para participarem de programas sociais e voluntariado empresarial: um exame com base na Teoria da Expectância [dissertação]. Recife: Faculdade Boa Viagem; 2006, 149 p.

MASLOW, Abraham H. Introdução à Psicologia do Ser. Rio de Janeiro: Eldorado, 1962. 
PORTO, Juliana Barreiros; TAMAYO, Álvaro. Escala de Valores Relativos ao Trabalho - EVT. Psicologia: Teoria e Pesquisa, Brasília, v.19 n.2, Mai/Ago. 2003:pp. 145-152.

RAOSOFT. Software de pesquisa na web para coleta de informações. Módulo de cálculo amostral. Atualizada em 01 jan. 2011. Acesso em 01 jan. 2011. Disponível em http://www.raosoft.com/samplesize.html.

SIQUEIRA, Mirlene Maria Matias; PADOVAM, Valquíria Aparecida Rossi. Bases Teóricas de Bem-Estar Subjetivo, Bem-Estar Psicológico e Bem-Estar no Trabalho. Psicologia: Teoria e Pesquisa, Brasília, 2008, Vol. 24 n. 2, PP. 201-209.

ZANELLA, Liane Carly Hermes. Metodologia da pesquisa. Apostila elaborada para o curso de administração na modalidade a distância. Brasília: UnB, 2006. 


\section{ANEXOS}

Anexo A - Inventário da Motivação e Significado do Trabalho (IMST)

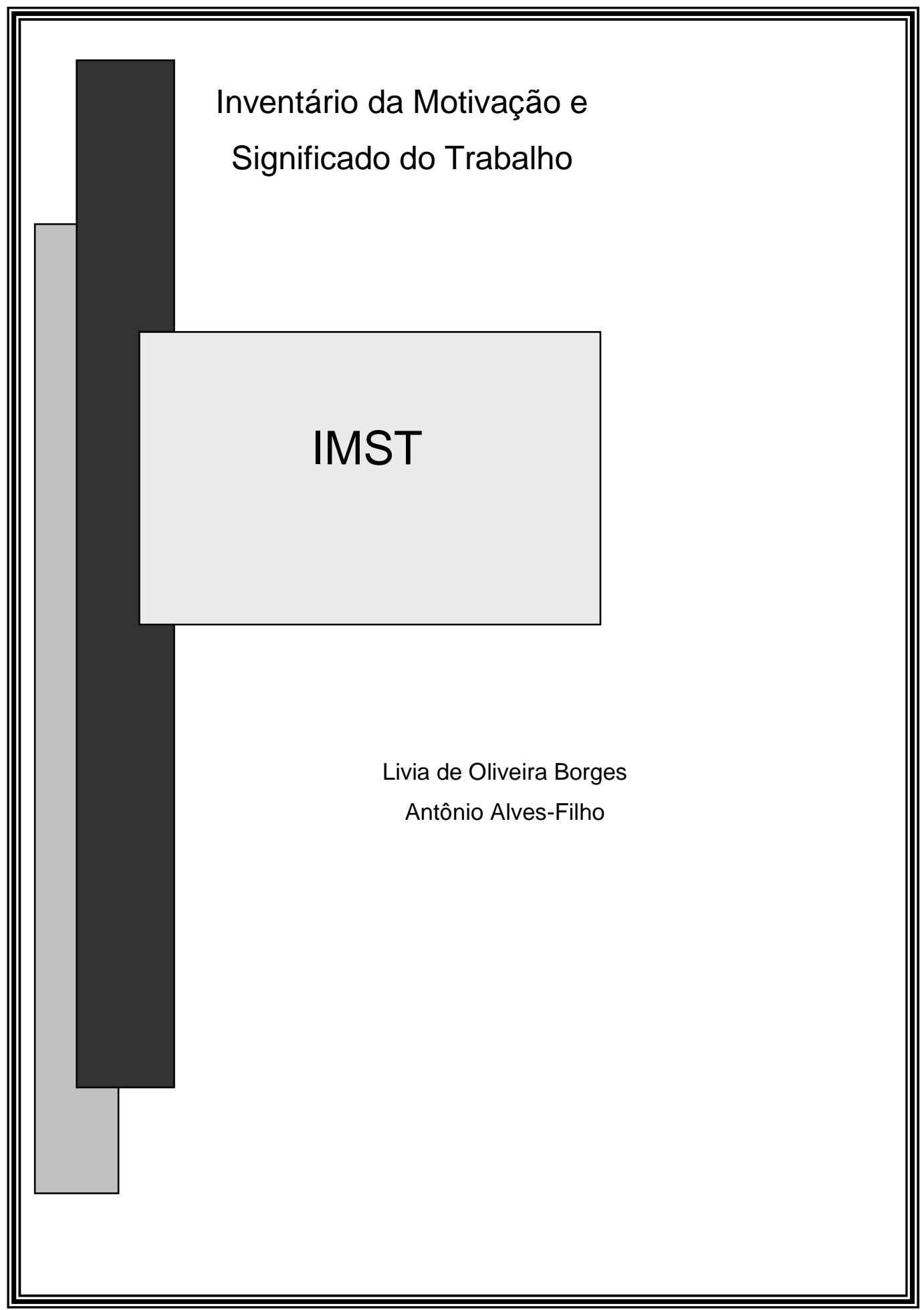


Caro participante, olá!

Temos o prazer de apresentá-lo ao Inventário da Motivação e do Significado do Trabalho (IMST). Este inventário tem o objetivo de ampliar a compreensão de suas relações com seu trabalho. Ele foi elaborado com base em pesquisas nas quais trabalhadores foram ouvidos em entrevista e em outras que testaram o uso e preenchimento do IMST, permitindo seu gradual aperfeiçoamento até o formato que você conhecerá agora.

\section{Instruções gerais}

Segue-se, então, o ISMT, o qual contém perguntas sobre o trabalho em várias perspectivas: como deve ser (trabalho ideal), suas expectativas (o que você espera dele), como é na realidade e como você percebe seu desempenho contribuindo para a obtenção de resultados desejados ou não. Por isso, o ISMT está dividido em três partes: a primeira aborda seu modelo ideal de trabalho; a segunda, suas expectativas e percepção do trabalho concreto e a terceira, sua percepção sobre seu desempenho.

O IMST foi elaborado baseados na confiança que temos em você, colaborador. Por isso, não há artifícios para o confundir. Talvez você sinta uma certa repetição, mas o que ocorre é que precisamos que opine sobre o mesmo aspecto do trabalho (por exemplo: salário e natureza das tarefas) nas quatro perspectivas de análise previstas.

Sinta-se inteiramente à vontade para dar suas opiniões. Não há previsão de respostas certas ou erradas, mas sim opiniões de pessoas diferentes. Assim, o que nos importa é sua opinião sincera. Por isso mesmo, é importante contar sua liberdade em responder ou não ao IMST. Sua decisão será, portanto, respeitada. Entenderemos o preenchimento do IMST, como seu livre consentimento.

Suas respostas serão ANÔNIMAS e mantidas em sigilo. Não escreva seu nome, nem assine os questionários.

As respostas serão analisadas em conjunto e de forma confidencial. 
Cada parte do IMST, a seguir, tem suas próprias instruções específicas. Antes de iniciar cada uma, preste bem atenção a tais instruções. Responda a todos os itens.

\section{Não deixe nada em branco}

\section{Primeira Parte}

A seguir, você vai encontrar uma lista de frases sobre o trabalho ou os resultados desse. Reflita quanto cada frase representa algo que o seu trabalho deve ser. Queremos saber como seria seu trabalho ideal. Indique-nos sobre esta sua avaliação atribuindo pontos de $\mathbf{0}$ a 4.

Vejamos antecipadamente os seguintes exemplos:

E1. 4 Trabalhar gera alegria de viver

E2. $\_$Trabalhando, fico com uma dor nas costas.

E3. 2 Trabalhando, sou criativo.

As respostas dadas significam que é de importância máxima o trabalho gerar Alegria de viver, que não é desejável que o trabalho gere Uma dor nas costas e que é desejável que o trabalho oportunize a expressão de sua criatividade, mas apenas moderadamente

Agora é sua vez de responder. Vamos lá! Opine: quanto (de 0 a 4) as frases contam algo que o trabalho deve ser?

$01 \ldots$ É um prazer realizar minhas tarefas

02 __ Tenho oportunidades de me tornar mais profissionalizado (mais qualificado).

03 ___ As pessoas sabem o quanto é importante o meu trabalho.

$04 \ldots$ Os chefes sabem se comunicar com cada um.

05 ___ O meu trabalho é o meu sustento.

06 ___ Sou independente porque assumo minhas despesas pessoais.

07 __ Os resultados do que faço beneficia os outros (usuários, clientes e pessoas em geral).

08 ___ Se trabalho, tenho o retorno econômico merecido. 
$09 \ldots$ Estou repetindo as mesmas tarefas todos os dias.

$10 \ldots$ Eu sinto que sou tratado como pessoa respeitada.

11 No meu trabalho são tomados todos os cuidados necessários à higiene do ambiente.

12 Fazendo minhas tarefas, não corro riscos físicos.

13 Eu Eu gosto de ver minhas tarefas prontas.

$14 \ldots$ Minhas opiniões sobre o trabalho são levadas em conta.

15 ___ Trabalhando, faço amizades.

16 Os chefes confiam em mim.

17 ___ Trabalhando, decido o que compro para mim.

18 _ $O$ trabalho me proporciona as principais assistências (transporte, educação, saúde, moradia, aposentadoria, etc.).

19 ___ Reconheço a autoridade dos superiores.

20 ___ A empresa cumpre obrigações para comigo.

$21 \_$Trabalhar exige esforço físico (corporal).

22 __ $\mathrm{O}$ trabalho é duro porque exige esforço, dedicação e luta.

23 ___ Minhas tarefas exigem de mim tentar fazer o melhor.

$24 \ldots$ O que ganho é suficiente e de acordo com meu esforço.

25 ___ O trabalho me torna uma pessoa digna.

26 ___ O trabalho é a garantia da existência humana.

27 Trabalho com conforto nas formas adequadas de higiene, disponibilidade de materiais, equipamentos adequados e conveniência de horário.

28 Fazendo minhas tarefas, tenho oportunidades permanentes de aprendizagem de novas coisas.

29 __ Meu corpo é necessário para executar minhas tarefas.

30 ___ Os colegas de trabalho me querem bem. 
$31 \ldots$ Meu trabalho é minha sobrevivência.

32 ___ Trabalhar bem é o que preciso fazer para continuar no meu emprego.

33 ___ Trabalho para ter assistência para mim e minha família.

$34 \ldots$ _ $O$ trabalho é a base para o progresso da sociedade.

35 __ O trabalho é para ser feito de acordo com o que dizem os superiores.

36 __ Todo dia faço tarefas parecidas.

37 ___ Trabalhando, estou usando meu pensamento para fazer as tarefas.

38 _ $\mathrm{O}$ trabalho é corrido quando se trabalha também em casa.

39 _ Trabalhar é fazer a tarefa.

40 ___ Trabalho de acordo com minhas possibilidades.

41 _ Todos os trabalhadores se esforçam como eu.

42 ___ Trabalhando, sinto-me como uma máquina ou um animal.

43 __ No meu trabalho são adotadas todas as medidas de segurança recomendáveis.

44 ___ Sou discriminado devido ao meu trabalho.

45 ___ Todos que trabalham têm os mesmos direitos.

46 ___ Esforço-me muito e ganho pouco.

$47 \ldots$ O trabalho me deixa esgotado.

48 __ Trabalhando, sinto-me atarefado.

49 ___ Sou reconhecido pelo que faço.

50 ___ Trabalho em ambiente limpo.

51 ___ Mereço ganhar mais pelo meu trabalho.

52 ___ No meu trabalho, estão sempre me exigindo rapidez.

53 __ No meu trabalho, tenho as ferramentas necessárias.

54 ___ Recebo toda assistência que mereço. 
55 _ Tenho que terminar minhas tarefas com pressa.

$56 \_$Sinto-me produtivo.

57 ___ Trabalhando, desenvolvo minhas habilidades interpessoais.

58 __ Influencio nas decisões da organização (contribuindo para a formação de opiniões).

59. ___ Sigo as normas das organizações (empresas).

60. ___ Trabalhando, tenho oportunidades de expressão de minha criatividade.

61. ___ O trabalho me garante receber meu salário. 


\section{Segunda parte}

Agora você vai refletir sobre vários resultados do trabalho, procurando responder a duas questões:
A) Quanto você espera que o seu trabalho apresente o resultado indicado?
B) Quanto ocorre concretamente no seu trabalho o resultado indicado?

Você responderá a estas questões atribuindo também pontos de 0 a 4 . Vejamos os exemplos para que esteja mais seguro ao apresentar suas respostas:

Quadro de exemplos

\begin{tabular}{l|c|c}
\hline Resultados gerados pelo trabalho & Espero & Ocorre \\
\hline E1. Alegria de viver & 2 & 0 \\
E2. Uma dor nas costas & 3 & 4 \\
E3. Criatividade & 3 & 1 \\
\hline
\end{tabular}

As respostas dos exemplos significam que você espera com moderação que o trabalhe gere Alegria de viver e que nunca observa, de fato, isto acontecer. Quanto a Uma dor nas costas espera mais intensamente (mais não ao máximo) isto acontecer e observa ocorrer sempre ou intensamente. Tem a mesma expectativa em relação à criatividade no seu trabalho, porém observa ocorrer apenas raramente.

Agora que você já compreendeu, vamos lá! Aproveite a oportunidade para nos contar quanto você espera e quanto você observa ocorrer o resultado indicado onde você trabalha. 


\begin{tabular}{|c|c|c|}
\hline Trabalhando, obtenho: & Espero & Ocorre \\
\hline 01. Prazer pela realização de minhas tarefas. & & \\
\hline $\begin{array}{l}\text { 02. Oportunidades de me tornar mais profissionalizado } \\
\text { (mais qualificado). }\end{array}$ & & \\
\hline 03. Reconhecimento da importância do que faço. & & \\
\hline 04. Boa comunicação dos chefes comigo. & & \\
\hline 05. Meu sustento. & & \\
\hline $\begin{array}{l}\text { 06. Independência para assumir minhas despesas } \\
\text { pessoais. }\end{array}$ & & \\
\hline 07. Estabilidade no emprego. & & \\
\hline $\begin{array}{l}\text { 08. Benefício para os outros (usuários, clientes e } \\
\text { pessoas em geral). }\end{array}$ & & \\
\hline 09. Retorno econômico merecido. & & \\
\hline 10. Repetição diária de tarefas. & & \\
\hline 11. O uso de meu pensamento ou da cabeça. & & \\
\hline 12. O sentimento de ser tratada como pessoa respeitada. & & \\
\hline $\begin{array}{l}\text { 13. Cuidados necessários à higiene no ambiente de } \\
\text { trabalho. }\end{array}$ & & \\
\hline 14. Minhas opiniões levadas em conta. & & \\
\hline 15. A confiança dos chefes em mim. & & \\
\hline 16. Crescimento pessoal na vida. & & \\
\hline 17. Independência para decidir o que compro para mim. & & \\
\hline $\begin{array}{l}\text { 18. Assistência em transporte, educação, saúde, } \\
\text { moradia, aposentadoria, etc. }\end{array}$ & & \\
\hline $\begin{array}{l}\text { 19. Responsabilidade para enfrentar os problemas do } \\
\text { trabalho. }\end{array}$ & & \\
\hline 20. Reconhecimento da autoridade dos superiores. & & \\
\hline 21. Ocupação de meu tempo. & & \\
\hline 22. Esforço físico (corporal) na execução do trabalho. & & \\
\hline 23. Dureza, pela exigência de esforço, dedicação e luta. & & \\
\hline 24. Exigência de tentar fazer o melhor. & & \\
\hline
\end{tabular}




\begin{tabular}{|c|c|c|}
\hline Trabalhando, obtenho: & Espero & Ocorre \\
\hline \multicolumn{3}{|l|}{$\begin{array}{l}\text { 25. Percepção de que ganho o suficiente e de acordo } \\
\text { com meu esforço. }\end{array}$} \\
\hline \multicolumn{3}{|l|}{ 26. Sentimento de que sou uma pessoa digna. } \\
\hline \multicolumn{3}{|l|}{$\begin{array}{l}\text { 27. Conforto nas formas de higiene, disponibilidade de } \\
\text { materiais, equipamentos adequados e conveniência de } \\
\text { horário. }\end{array}$} \\
\hline \multicolumn{3}{|l|}{$\begin{array}{l}\text { 28. Oportunidades permanentes de aprendizagem de } \\
\text { novas coisas. }\end{array}$} \\
\hline \multicolumn{3}{|l|}{ 29. Responsabilidades por minhas decisões. } \\
\hline \multicolumn{3}{|l|}{ 30. Minha sobrevivência. } \\
\hline \multicolumn{3}{|l|}{ 31. Permanência no emprego pela qualidade do que faço. } \\
\hline \multicolumn{3}{|l|}{ 32. Assistência para mim e minha família. } \\
\hline \multicolumn{3}{|l|}{ 33. Contribuição para o progresso da sociedade. } \\
\hline \multicolumn{3}{|l|}{ 34. Obediência aos superiores. } \\
\hline \multicolumn{3}{|l|}{ 35. Tarefas parecidas diariamente feitas } \\
\hline \multicolumn{3}{|l|}{ 36. Percepção de estar ocupado, fazendo alguma coisa. } \\
\hline \multicolumn{3}{|l|}{$\begin{array}{l}\text { 37. Uma vida corrida quando se trabalha também em } \\
\text { casa. }\end{array}$} \\
\hline \multicolumn{3}{|l|}{ 38. Tarefa cumprida. } \\
\hline \multicolumn{3}{|l|}{$\begin{array}{l}\text { 39. Tarefas e obrigações de acordo com minhas } \\
\text { possibilidades. }\end{array}$} \\
\hline \multicolumn{3}{|l|}{ 40. Sentimento de ser como uma máquina ou um animal. } \\
\hline \multicolumn{3}{|l|}{$\begin{array}{l}\text { 41. Adoção de todas as medidas de segurança } \\
\text { recomendáveis no meu trabalho. }\end{array}$} \\
\hline \multicolumn{3}{|l|}{ 42. Discriminação pelo meu trabalho. } \\
\hline \multicolumn{3}{|l|}{ 43. Igualdade de direitos para todos que trabalham. } \\
\hline \multicolumn{3}{|l|}{$\begin{array}{l}\text { 44. Percepção de que ganho pouco para o esforço que } \\
\text { faço. }\end{array}$} \\
\hline \multicolumn{3}{|l|}{ 45. Sentimento de que estou esgotado. } \\
\hline 46. Sentimento de que sou gente. & & \\
\hline
\end{tabular}




\begin{tabular}{|c|c|c|}
\hline Trabalhando, obtenho: & Espero & Ocorre \\
\hline \multicolumn{3}{|l|}{ 47. Percepção de que estou atarefado. } \\
\hline \multicolumn{3}{|l|}{ 48. Reconhecimento pelo que faço. } \\
\hline \multicolumn{3}{|l|}{ 49. Limpeza no ambiente de trabalho. } \\
\hline \multicolumn{3}{|l|}{ 50. Merecimento de ganhar mais pelo que faço. } \\
\hline \multicolumn{3}{|l|}{ 51. Sentimento de estar bem de cabeça (mentalmente). } \\
\hline \multicolumn{3}{|l|}{ 52. Exigência de rapidez. } \\
\hline \multicolumn{3}{|l|}{ 53. Equipamentos necessários e adequados. } \\
\hline \multicolumn{3}{|l|}{ 54. Assistência merecida. } \\
\hline \multicolumn{3}{|l|}{ 55. Oportunidade de exercitar o meu corpo. } \\
\hline \multicolumn{3}{|l|}{ 56. Pressa em fazer e terminar minhas tarefas. } \\
\hline \multicolumn{3}{|l|}{ 57. A percepção de ser produtivo. } \\
\hline \multicolumn{3}{|l|}{$\begin{array}{l}\text { 58. Desenvolvimento das minhas habilidades } \\
\text { interpessoais. }\end{array}$} \\
\hline \multicolumn{3}{|l|}{$\begin{array}{l}\text { 58. Desenvolvimento das minhas habilidades } \\
\text { interpessoais. }\end{array}$} \\
\hline \multicolumn{3}{|l|}{$\begin{array}{l}\text { 58. Desenvolvimento das minhas habilidades } \\
\text { interpessoais. }\end{array}$} \\
\hline \multicolumn{3}{|l|}{$\begin{array}{l}\text { 59. Influência nas decisões (contribuindo para a } \\
\text { formação de opiniões). }\end{array}$} \\
\hline \multicolumn{3}{|l|}{$\begin{array}{l}\text { 60. Cumprimento das normas e obrigações da } \\
\text { organização (empresa) para comigo. }\end{array}$} \\
\hline \multicolumn{3}{|l|}{ 61. Oportunidades de expressão de minha criatividade. } \\
\hline 62. Meu salário. & & \\
\hline
\end{tabular}




\section{Terceira Parte}

Atribuindo pontos de 0 a 4, novamente, a cada item da lista que se segue, conte-nos agora: Quanto o que você obtém do seu trabalho depende de seu desempenho e/ou de seu esforço?

01 _ Prazer pela realização de minhas tarefas.

02 _ Oportunidades de me tornar mais profissionalizado (mais qualificado).

03 __ Reconhecimento da importância do que faço.

04 __ Boa comunicação dos chefes comigo.

05 _ Meu sustento.

06 __ Independência, porque assumo minhas despesas pessoais.

07 __ Estabilidade no emprego (emprego garantido).

08 _ Benefício para os outros (usuários, clientes e pessoas em geral).

09 __ Sentimento de ser tratada como pessoa respeitada.

10 _ O gosto de ver minhas tarefas prontas.

11 _ Minhas opiniões levadas em conta.

12 Amizades feitas no trabalho.

13 _ A confiança dos chefes em mim.

14 _ Assistência em transporte, educação, saúde, moradia, aposentadoria, etc.

15 __ Responsabilidade para enfrentar os problemas do trabalho.

16 _ Reconhecimento da autoridade dos superiores

17 __ Ocupação de meu tempo.

18 __Esforço físico (corporal) na execução do trabalho.

19 __ Exigência de tentar fazer o melhor.

20 __ Percepção de que ganho o suficiente e de acordo com meu esforço.

21 _ Sentimento de que sou uma pessoa digna. 
22 _ Conforto nas formas adequadas de higiene, disponibilidade de materiais, equipamentos e conveniência de horário.

23 __ Oportunidades permanentes de aprendizagem de novas coisas.

24 _ Responsabilidades por minhas decisões.

25 __ O uso meu corpo e/ou das minhas energias físicas para executar minhas tarefas.

26 __ Sentimento de ser querido pelos colegas de trabalho.

27 __ Permanência no emprego pela qualidade do que faço.

28 __ Assistência para mim e minha família.

29 __ Contribuição para o progresso da sociedade.

30 __ Obediência aos superiores.

31 __ Uma vida corrida quando se trabalha também em casa.

32 _ Tarefa cumprida.

33 __ lgualdade de esforços entre todos os trabalhadores.

34 _ Sentimento de ser uma máquina ou um animal.

35 _ Adoção de todas as medidas de segurança recomendáveis no meu trabalho.

36 __ Discriminação pelo meu trabalho.

37 _ Igualdade de direitos para todos que trabalham.

38 __ Sentimento de que estou esgotado.

39 __ Sentimento de que sou gente.

40 __ Percepção de que estou atarefado.

41 L_ Limpeza no ambiente de trabalho.

42 __ Equipamentos necessários e adequados.

43 ___ Assistência merecida.

44 _ A percepção de ser produtivo.

45 __ Desenvolvimento das minhas habilidades interpessoais.

46 __ Influência nas decisões (contribuindo para a formação de opiniões). 
47 _ Cumprimento das normas e obrigações da organização (empresa) para comigo.

48 __ Meu salário. 